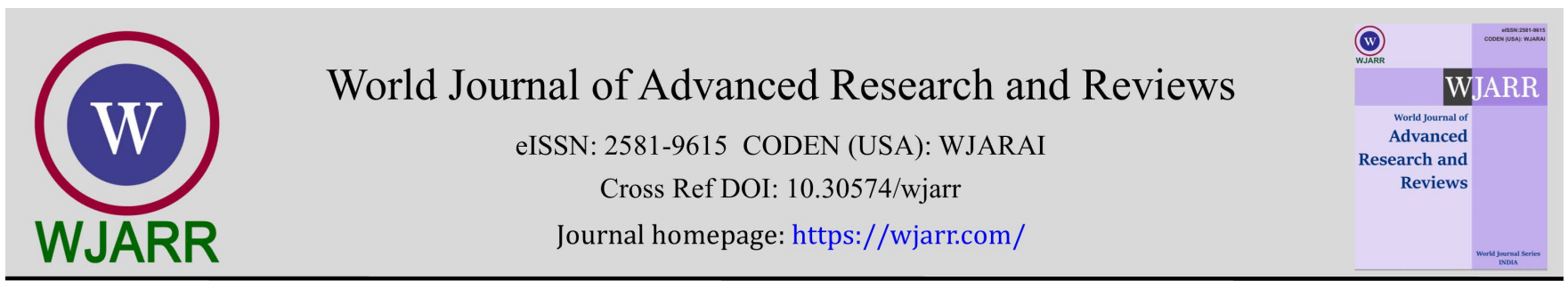

(RESEARCH ARTiClE)

\title{
Molecular docking studies of dihydropyridazin-3(2H)-one derivatives as Antifungal, antibacterial and anti-helmintic agents
}

\author{
Manish Devgun, Sushil Prasad, SukhbirLal Khokra *and Rakesh Narang \\ Institute of Pharmaceutical Sciences, Kurukshetra University, Kurukshetra, 136119, India.
}

World Journal of Advanced Research and Reviews, 2021, 12(01), 186-214

Publication history: Received on 20 August 2021; revised on 25 September 2021; accepted on 27 September 2021

Article DOI: https://doi.org/10.30574/wjarr.2021.12.1.0476

\begin{abstract}
Molecular docking is the identification of ligand's correct binding geometry i.e pose in the binding site and estimation of its binding affinity for the rational design of drug molecule. The current study endeavored the high throughput insilico screening of 24 compounds docked with their respective protein using PyRx-Virtual Screening Tool software. Out of 24 compounds, almost all test compounds showed a very good binding affinity score. Fluconazole was used as a standard drug in case of Antifungal, Ciprofloxacin in case of Antibacterial, and Albendazole in case of Antihelmintics. More negative is the binding free energy score, more favorable is the pose for binding to protein active site. Based on $\mathrm{H}$-bond interactions of these 24 compounds, Compounds $3 \mathrm{a} 5,3 \mathrm{c} 3,3 \mathrm{~d} 5,3 \mathrm{~d} 6$ were found to be the similar outcome for antifungal activity as fluconazole, Compound3a1 for antibacterial, and Compounds 3b5, 3d6 for the antihelmintic agent. Furthermore, the affinity of any small ligand molecules can be considered as an extraordinary tool in the field of drug design and offer imminent in future examination to build up potent antimicrobial agents.
\end{abstract}

Keywords:PyRx; Fluconazole; Ciprofloxacin; Albendazole; Antimicrobial

\section{Introduction}

The arrival of new medication into a market will take an average of 10-15 years and about US \$2 billion. Traditional approaches of drug discovery relied on chemical entities which were obtained from natural products and the whole process was time-consuming and perhaps less economical[1]. These drawbacks allow the shift of the traditional approach to combinatorial and insilico approaches, which supported the assistance in structural information[2]. These new advancements play an essential role in reducing expense and the hour of early drug discovery [3]. Structural and Ligand-based methodologies are the most important techniques in drug designing and virtual screening in CADD. Structure-based drug design relies on the understanding of $3 \mathrm{~d}$ structure of protein acquired through NMR, XRayCrystallography, and any other technique while ligand-based drug designing is based on pharmacophore modeling and Quantitative Structural Activity Relationship(QSAR)[4]. The molecular docking technique determines binding interaction between protein molecule and optimum conformation of ligand molecule so that overall energy of system undergoes minimization to form a stable complex[5]. Ideally, Computational docking gives prediction about binding affinity and interaction with protein's active site before the compound is synthesized[6]. Hence, reduce the cost of money and material for the synthesis.

\subsection{Types of drug design}

Drug design includes two important types

- $\quad$ Structure-based drug design

\footnotetext{
${ }^{*}$ Corresponding author: SukhbirLal Khokra

Institute of Pharmaceutical Sciences, Kurukshetra University, Kurukshetra,136119, India
}

Copyright (C) 2021 Author(s) retain the copyright of this article. This article is published under the terms of the Creative Commons Attribution Liscense 4.0. 
- $\quad$ Ligand-based drug design.

\subsubsection{Structure-Based Drug Designing}

It depends on an understanding of the 3D structure of protein acquired through NMR, X-RayCrystallography and any other technique. If the target protein is not at reach, homology modeling on that protein is created based on experimentally related protein in that series[7]. This also encouraged the rapid development in Structure-Based Drug Design.

Two methods-First includes "Finding" ligand for a given protein also called as database searching.The primary benefit of this technique is that it saves manual efforts to get novel leads.

The second is the "Building" ligand also known as ReceptorBased Drug Designing. The main advantage of this method includes ligands that are not present in any of the databases that must be proposed.

\subsubsection{Ligand-based drug designing}

It depends on the information of another ligand that binds to the same pocket of the protein. These ligands give an idea about a minimum pharmacophoric qualification that would be possessed by a ligand molecule for binding to the biological target. Additionally, a QSAR in which correlation between experimentally observed characteristics and calculated properties must be obtained. The QSAR assumes an indispensable part in the prediction of the activity of new analog.

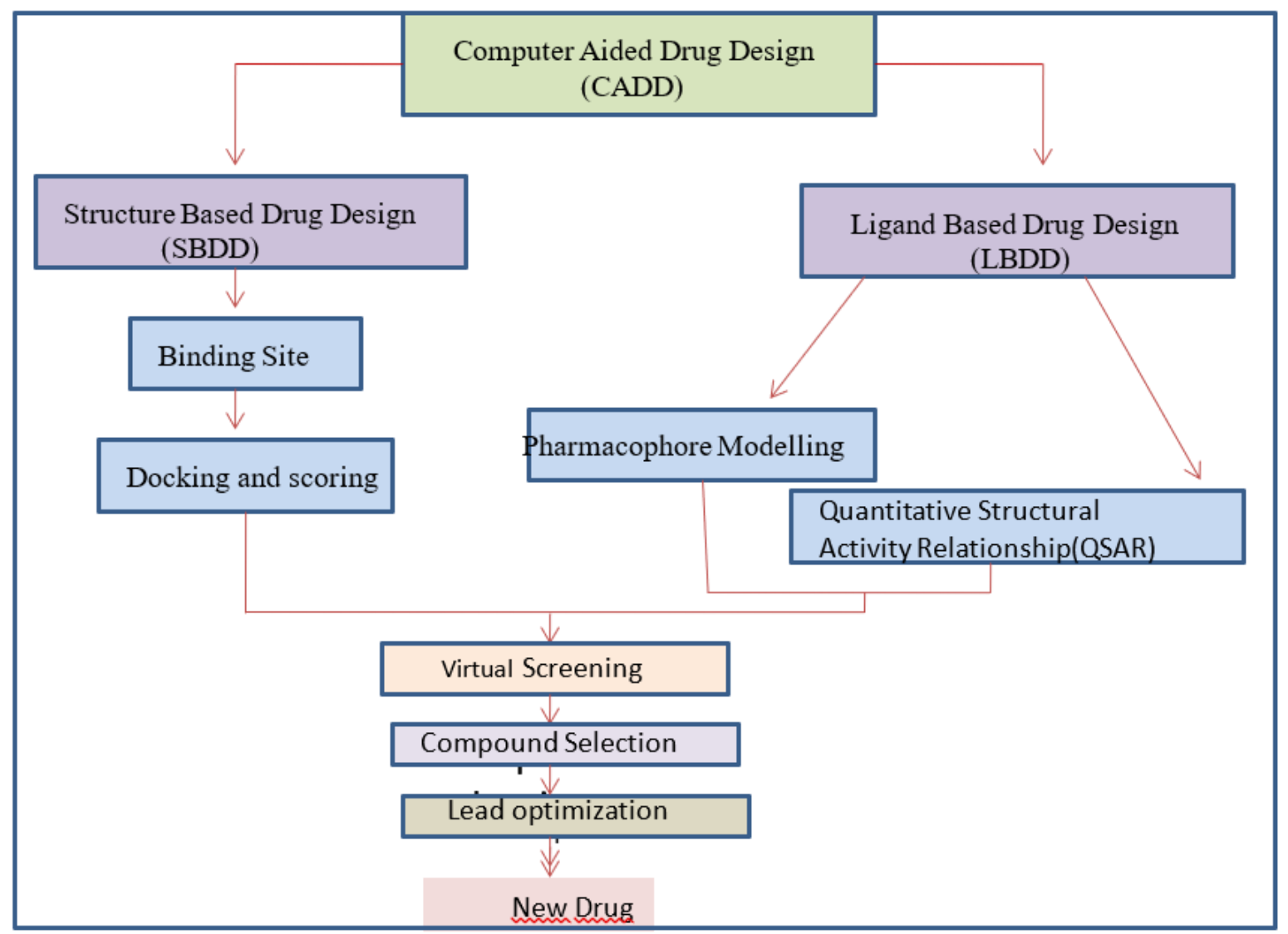

Figure 1 Computer-Aided Drug Design

\section{Docking studies}

Traditional approaches were extremely high-ticket, more time-consumption, and fewer economical to discover a modern clinical drug. To overcome the disadvantage of ancient strategies, simpler and rational strategies are introduced that deem virtual screening, supported the provision of structure details. Virtual screening approaches are also known as structure and ligand-based product design techniques [8].The structural approachto drugs, explains molecular 
linking up while ligand-based approaches discuss the interaction between quantitative structure response (QSAR) and pharmacophore modeling. The docking method describes the connection between the material and the target molecule.

\section{Three categories of Molecular docking}

Induced fit docking-Here receptor site is assumed to be adjustable in nature. The ligand binds flexibly at the active site of the receptor with maximum binding affinity, implementing the concept of complementarity between ligand and protein molecule[9].

Lock and Key docking- Both ligand and receptor are assumed rigid and are closely bound. This model also explains $3 \mathrm{~d}$ complementarity between receptor and ligand[10].

Ensemble docking-Based on complexity and flexibility of conformational state of proteins. Many protein structures are utilized as an associate degree for docking with ligand[11], [12].

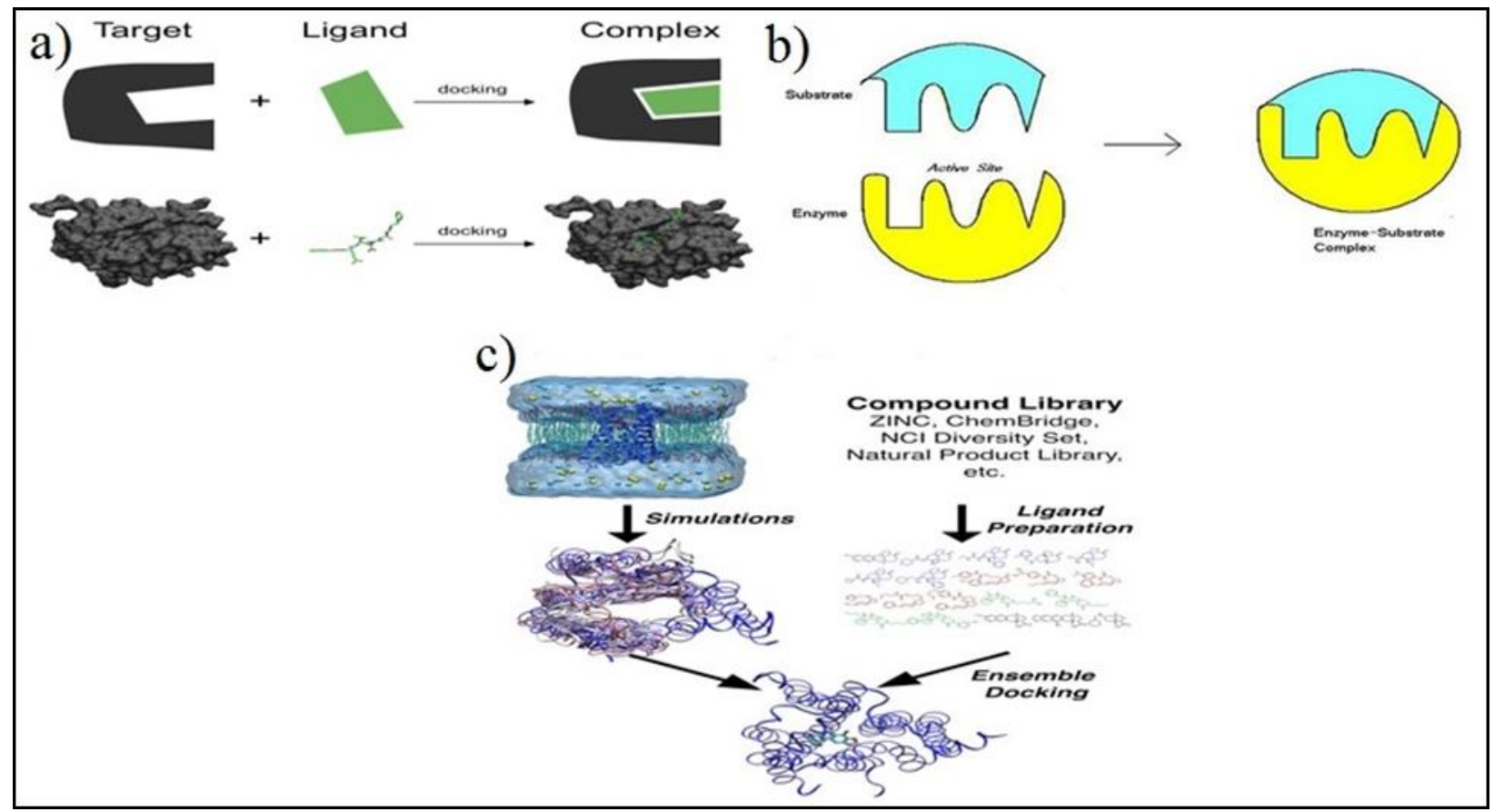

Figure 2 Techniques of molecular docking:(a) Induced work docking; (b) Lock and key docking; and (c) Ensemble docking

The current objective is to determine compounds having a good binding affinity towards various proteins(Antifungal, Antibacterial, Antihelmintics). Based on the result obtained, the compounds having significant binding affinity were synthesized and evaluated for biological activity. Numerous researches explored that presence of an aryl group with one or more electron-donating groups or the presence of an imino group in a six-membered ring is vital for various biological activities. This results in the synthesis of novel pyridazinones derivatives and evaluation of their activities. The pyridazinone derivatives show a wide range of biological activities and may act as a biological active pharmacophore in medicinal chemistry[13]-[15]. This moiety may help in finding new medications of likely restorative therapeutic value. To find a significant activity, molecular docking is used which predicts Binding Affinity scores of different ligands interacting with protein. The basic structure of 4,5-Dihydropyridazin-3(2H)-one is shown below in Fig.3. 


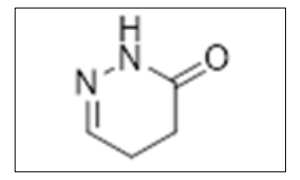

Figure 3 Basic Structure of 4, 5-dihydropyidazin-3(2H)-one

\section{The Target for Antifungal, Antibacterial, and Antihelmintic drugs}

In silico docking investigation of 24 compounds gave us an idea regarding novels responsible for the antifungal, antibacterial, and antihelmintic activity. The results obtained demonstrated that all examined ligand molecules have position and orientation inside the putative binding site of Antifungal (PDB ID-5TZ1), Antibacterial (PDB ID-1JXA), Antihelmintic (PDB ID-10J0) which delivers a passage channel for the substrate to the active site. There is a strong connection between the affinity of the ligand towards protein and binding free energy which can contribute to understanding and interpreting the activity of ligand by various possible mechanisms.

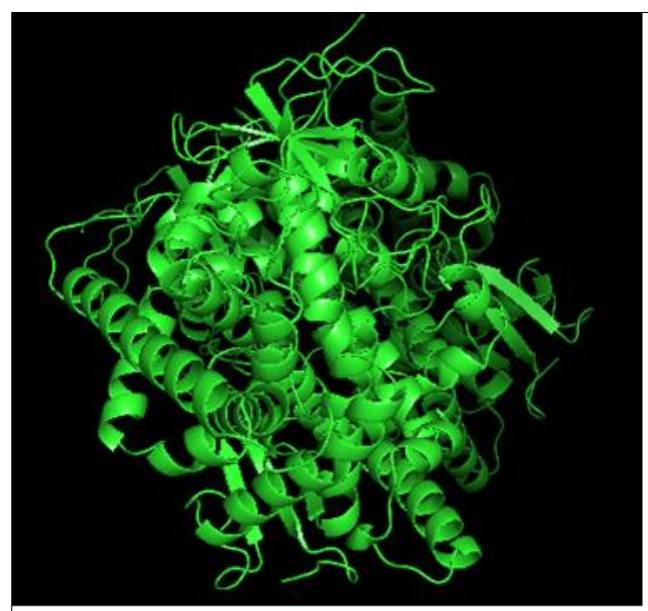

PDB ID- 5TZ1

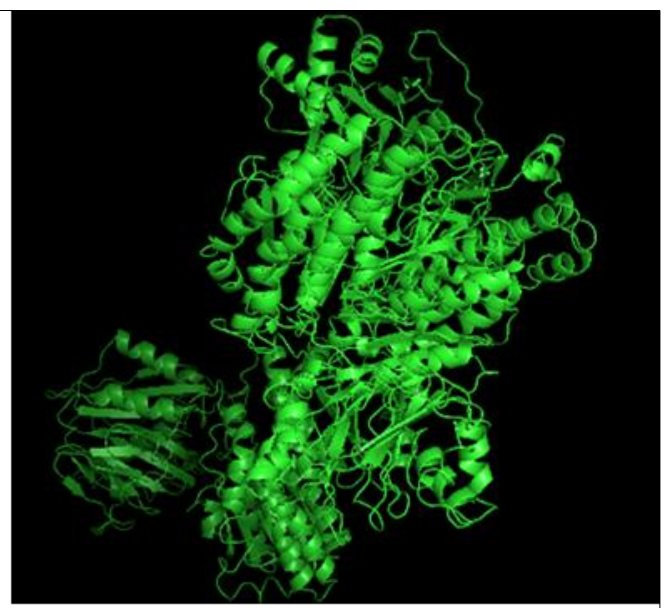

PDB ID-1JXA

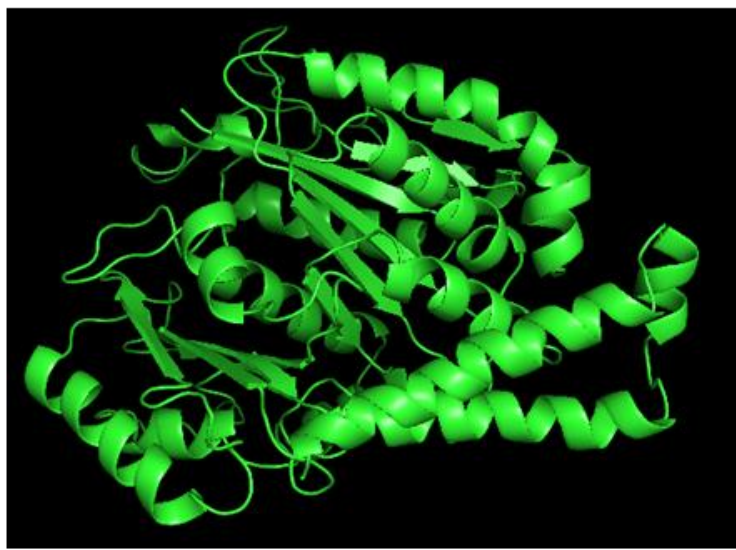

PDB ID- 10J0

Figure 4 3d view of PDB's

\section{Methodology}

Finding the optimum binding mode of ligand to receptor site is the main objective of docking. Docking studies have been performed with a group of theoretic pyridazinone derivatives using PyRx-Virtual Screening Tool on protein with PDB ID-5TZ1(Antifungal),1JXA(Antibacterial),10J0(Antihelmintic). The protein structure has been imported from https://www.rcsb.org/structure/5TZ1 for antifungal, https://www.rcsb.org/structure/1JXA for antibacterial and 
https://www.rcsb.org/structure/10J0 for antihelmintic. The structure of various 4,5-Dihydro pyridazine-3(2H)-ones analogs is shown in table 1.

\subsection{Steps Involved}

- Importing a protein file and protein preparation

- Preparation of ligands using MarvinSketch 5.11.0

- Detecting cavities of protein molecules

- Execution of docking through Vina Wizard

- Determination of various poses of ligand on the protein molecule

- Determination of Binding Affinity Scores

- Determination of protein residue responsible for binding and hydrogen bond interaction

\subsection{Compound Selection}

Based on experimental data, we chose 24 hypothetical compounds, and docking was performed using protein with PDB ID-5TZ1(Antifungal),1JXA(Antibacterial),10J0(Antihelmintic) using PyRx-Virtual Screening Tool. Nonetheless, all hypothetical ligands were found to have moderate outcomes; however out of 24 compounds, Compound 3a5, 3c3, 3d5, $3 \mathrm{~d} 6$ for antifungal; Compound 3a1 for antibacterial; Compound 3b5,3d6 were found to be the potent outcome for antihelmintic activity. The docking output of 24 compounds is mentioned in Table 2.

\subsection{Preparation of Ligand}

Preparation of ligand molecules was done by Chem Draw Professionals 15.0 and Marvin Sketch. The molecules were converted into $2 \mathrm{~d}$ and then $3 \mathrm{~d}$ using the build and optimize the method. The obtained structure will be saved in PDB format. This step involved the preparation of ligand molecules and was assigned bond, bond order, hybridization charges, free hydrogens, and flexible torsions. The generated 3d structure was imported in PyRx-Virtual Screening Tool for docking.

\subsection{Set of Hypothetical Compounds}

The docking study was performed with a set of hypothetical 4,5-Dihydropyridazin-3(2H)-one derivatives. The basic moiety is shown below in fig.3.The structure of all 24 compounds with Binding Affinity Scores is illustrated in table 2.

\subsection{Protein Preparation}

The protein used was imported from https://www.rcsb.org/structure/5TZ1,https://www.rcsb.org/structure/1JXA, https://www.rcsb.org/structure/10J0 and protein preparation was done by using discovery studio 2021 client software. All water molecules,co-crystallized ligand, and other chemical compounds were removed from the main protein structure. Different interactions are considered to calculate the binding affinity score between receptors and ligands.

\subsection{Docking performance}

All designed ligands and reference drugs were assigned within Vina Wizard and then Autodock wizard and necessary bond, bond order, hybridization, polar charges, etc were allotted using the corresponding software. Docking of ligand was performed by generating many conformations of the ligand within the active site and the score of different conformation within the active site should be noted down based on various interactions between ligand and receptor.

Binding affinity is generally influenced by non-covalent intermolecular interactions such as VanderWaal interactions, electrostatic interactions, hydrophobic interactions, and hydrogen bonding between two molecules. Likewise, the binding affinity between a ligand and the receptor's active site might also be influenced by the presence of different other molecules. 
Table 1 Structure of 24 Hypothetical Ligands

Compound No.


World Journal of Advanced Research and Reviews, 2021, 12(01), 186-214

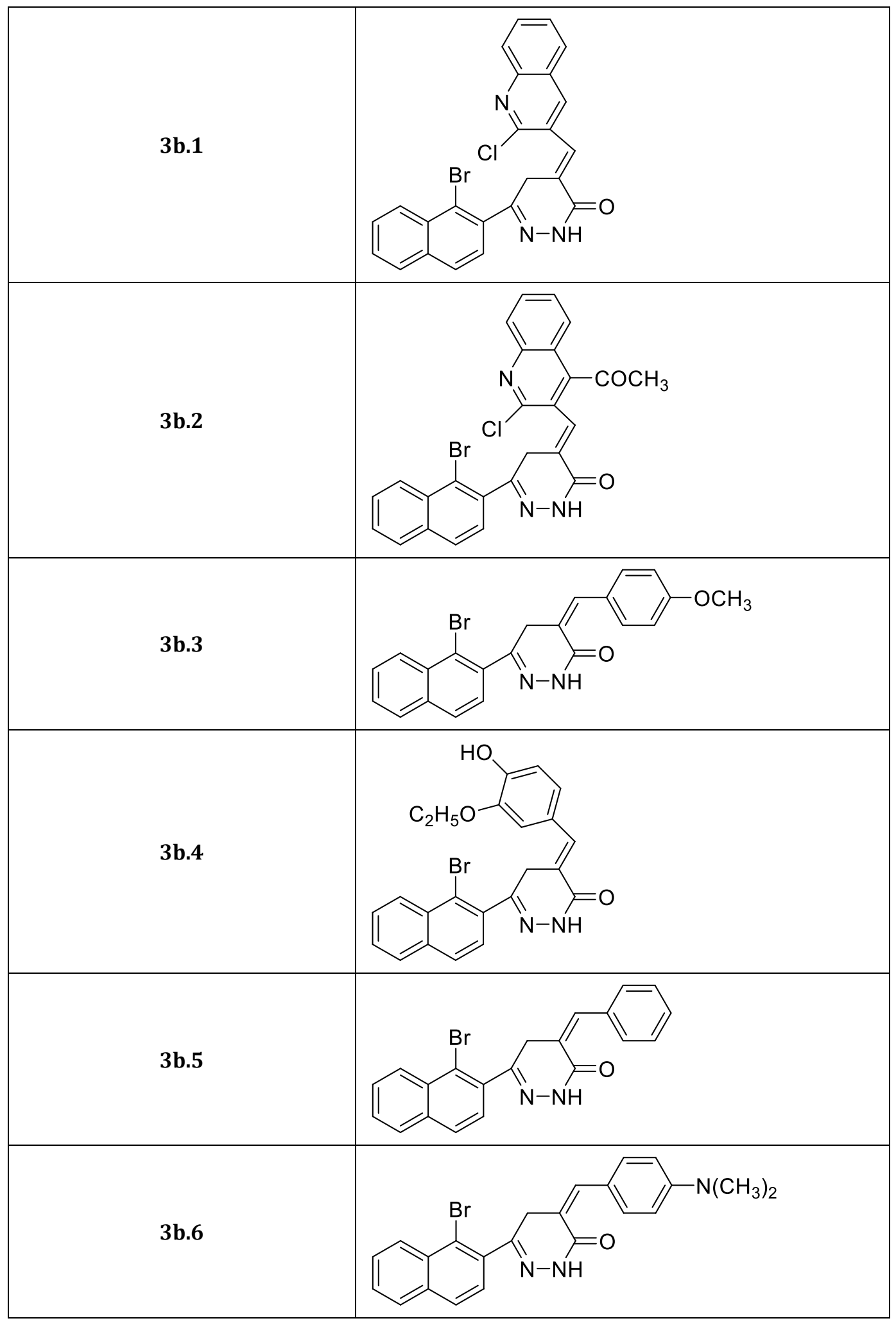


World Journal of Advanced Research and Reviews, 2021, 12(01), 186-214

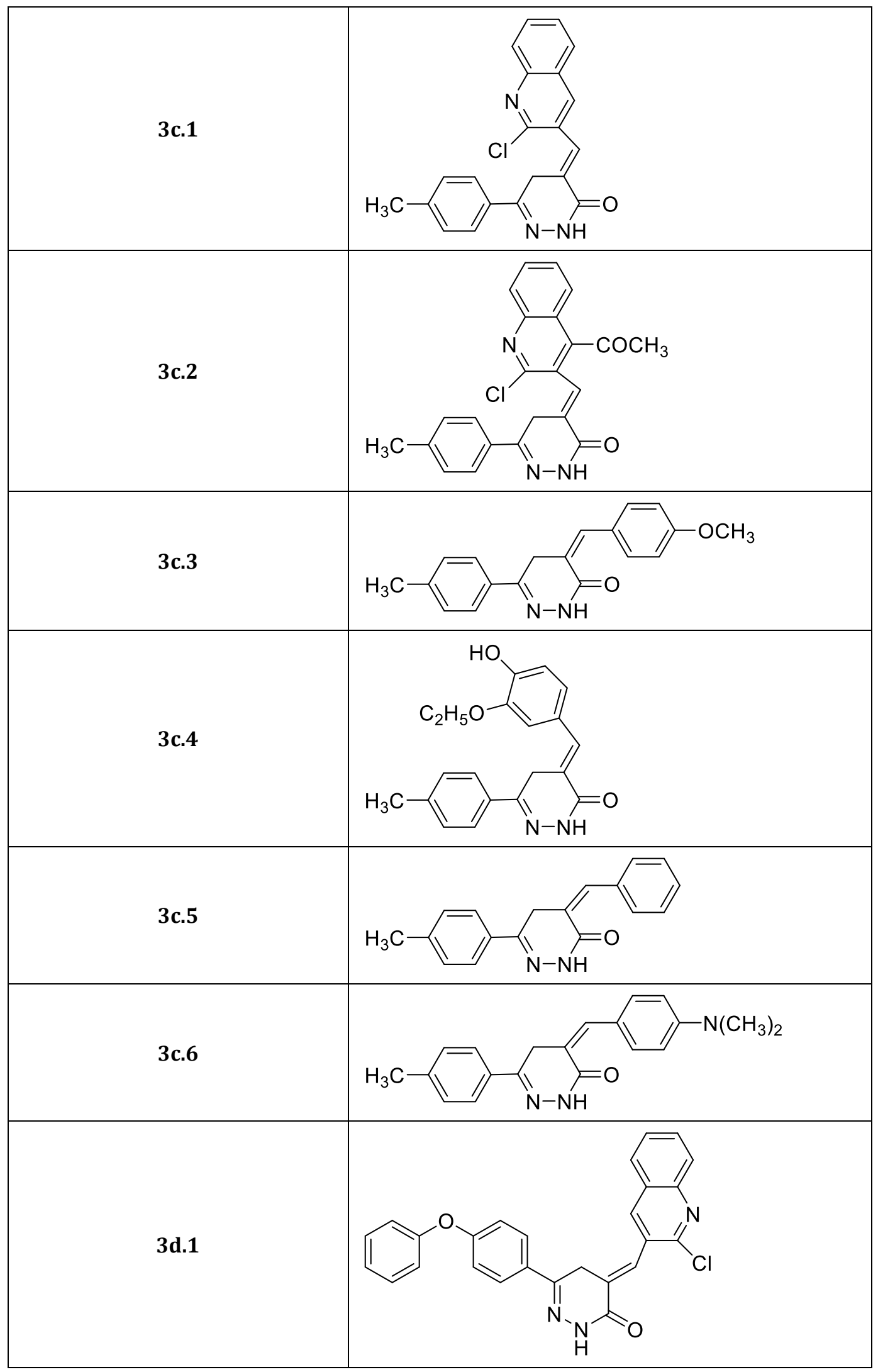


World Journal of Advanced Research and Reviews, 2021, 12(01), 186-214

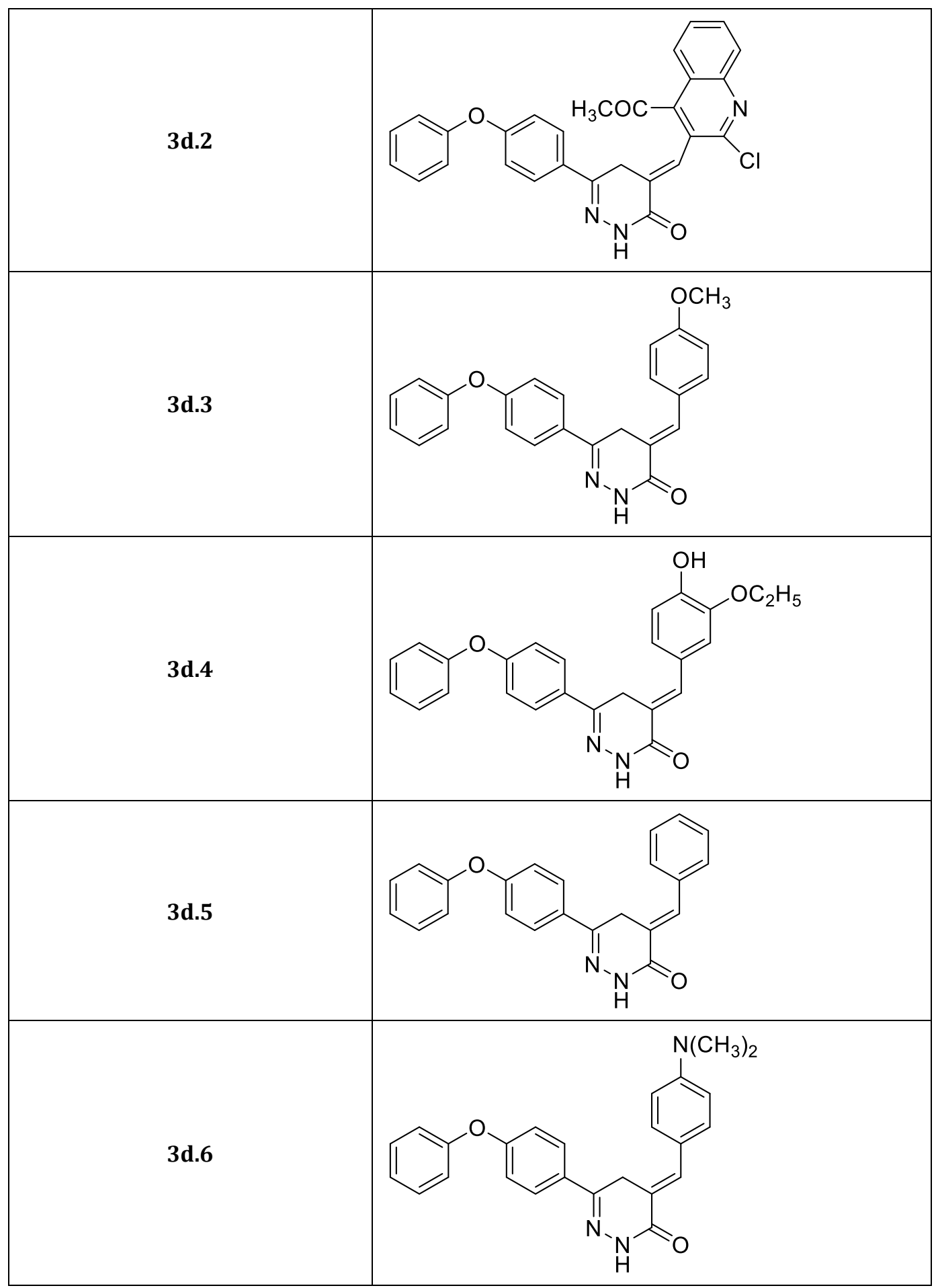


Table 2 Ligand-receptor interaction data of Dihydropyridazin-3(2H)-one on PDB ID: 5TZ1 using PyRx-Virtual Screening Tool

\begin{tabular}{|c|c|c|c|}
\hline Sr. No. & $\begin{array}{l}\text { Interaction of amino } \\
\text { acid having a shortest } \\
\text { bond length ( } *_{-} \\
\text {indicates H-bond } \\
\text { interacting amino } \\
\text { acid) }\end{array}$ & $\begin{array}{l}\text { Number of hydrogen } \\
\text { bond interactions }\end{array}$ & Binding affinity score \\
\hline \multirow{3}{*}{ Fluconazole } & Tyr132B(2.92) & \multirow{3}{*}{2} & \multirow{3}{*}{-7.3} \\
\hline & $\operatorname{Arg} 469 B(2.30)^{*}$ & & \\
\hline & Phe463B(2.28)* & & \\
\hline \multirow{10}{*}{ 3a.1 } & Ala62A(5.03) & \multirow{10}{*}{1} & \multirow{10}{*}{-12.5} \\
\hline & Phe58A(5.58) & & \\
\hline & Ile55A(5.42) & & \\
\hline & $\operatorname{Trp54B(5.38)}$ & & \\
\hline & Tyr53A(3.86) & & \\
\hline & $\operatorname{Trp54A(4.42)}$ & & \\
\hline & Phe52A(2.72)* & & \\
\hline & Lys78A(4.53) & & \\
\hline & Ala62B(3.98) & & \\
\hline & Ile55B(5.41) & & \\
\hline \multirow{6}{*}{ 3a.2 } & Lys78A(4.26) & \multirow{6}{*}{0} & \multirow{6}{*}{-12.1} \\
\hline & Ala62B(3.88) & & \\
\hline & Ile55B(5.21) & & \\
\hline & Ile55A(4.42) & & \\
\hline & $\operatorname{Trp} 54 A(4.32)$ & & \\
\hline & Phe52A(2.22) & & \\
\hline \multirow{6}{*}{$3 a .3$} & Met508B(4.76) & \multirow{6}{*}{0} & \multirow{6}{*}{-12.0} \\
\hline & Leu121B(2.20) & & \\
\hline & Ala61B(2.80) & & \\
\hline & Val234B(4.60) & & \\
\hline & Leu87B(3.20) & & \\
\hline & Leu88B(3.11) & & \\
\hline \multirow{3}{*}{ 3a. 4} & Val235B(3.22) & \multirow{3}{*}{0} & \multirow{3}{*}{-12.8} \\
\hline & Ala60B(3.70) & & \\
\hline & Met510B(2.80) & & \\
\hline \multirow{4}{*}{ 3a.5 } & Ser507A(3.04)* & \multirow{4}{*}{2} & \multirow{4}{*}{-11.8} \\
\hline & Met508A(2.53)* & & \\
\hline & Leu376A(5.42) & & \\
\hline & Leu121A(5.14) & & \\
\hline
\end{tabular}


World Journal of Advanced Research and Reviews, 2021, 12(01), 186-214

\begin{tabular}{|c|c|c|c|}
\hline & Tyr118A(3.74) & & \\
\hline & Leu87A(5.22) & & \\
\hline & Tyr64A(5.17) & & \\
\hline & Pro230A(4.79) & & \\
\hline \multirow{7}{*}{$3 a .6$} & Ser507A(2.67)* & \multirow{7}{*}{1} & \multirow{7}{*}{-11.7} \\
\hline & Met508A(2.99) & & \\
\hline & Pro230A(4.26) & & \\
\hline & Leu87A(5.42) & & \\
\hline & Tyr118A(4.36) & & \\
\hline & Leu121A(5.30) & & \\
\hline & Leu376A(2.63) & & \\
\hline \multirow{5}{*}{$3 \mathrm{~b} .1$} & Met508A(3.48) & \multirow{5}{*}{0} & \multirow{5}{*}{-10.9} \\
\hline & Leu121A(3.92) & & \\
\hline & Cys470A(3.1) & & \\
\hline & Ile379A(4.72) & & \\
\hline & Leu376A(5.05) & & \\
\hline \multirow{4}{*}{$3 \mathrm{~b} .2$} & Ala218A(3.42) & \multirow{4}{*}{0} & \multirow{4}{*}{-11.5} \\
\hline & Phe213B(5.47) & & \\
\hline & Ile197B(4.72) & & \\
\hline & Phe198B(4.49) & & \\
\hline \multirow{4}{*}{$3 \mathrm{~b} .3$} & Phe58A(4.96) & \multirow{4}{*}{0} & \multirow{4}{*}{-10.6} \\
\hline & Ala62A(5.37) & & \\
\hline & $\operatorname{Trp54B}(4.30)$ & & \\
\hline & Ala62B(4.90) & & \\
\hline \multirow{4}{*}{$3 b .4$} & Leu121A(3.82) & \multirow{4}{*}{0} & \multirow{4}{*}{-11} \\
\hline & Cys470A(3.1) & & \\
\hline & Ile379A(3.72) & & \\
\hline & Ile197B(4.32) & & \\
\hline \multirow{5}{*}{$3 \mathrm{~b} .5$} & Leu376A(4.97) & \multirow{5}{*}{0} & \multirow{5}{*}{-10.7} \\
\hline & Leu121A(5.26) & & \\
\hline & Tyr118A(4.45) & & \\
\hline & Ile131A(4.45) & & \\
\hline & Lys143A(5.28) & & \\
\hline \multirow{5}{*}{$3 \mathrm{~b} .6$} & Tyr64B(2.60)* & \multirow{5}{*}{1} & \multirow{5}{*}{-11.1} \\
\hline & Pro230B(5.34) & & \\
\hline & Met508B(4.88) & & \\
\hline & Ala61B(5.24) & & \\
\hline & Val234B(4.78) & & \\
\hline
\end{tabular}


World Journal of Advanced Research and Reviews, 2021, 12(01), 186-214

\begin{tabular}{|c|c|c|c|}
\hline \multirow{3}{*}{ 3c. 1} & Ile55A(3.98) & \multirow{3}{*}{0} & \multirow{3}{*}{-10.6} \\
\hline & $\operatorname{Trp54B}(3.56)$ & & \\
\hline & Ser74A(3.01) & & \\
\hline \multirow{9}{*}{$3 c .2$} & Lys143A(4.67)* & \multirow{9}{*}{1} & \multirow{9}{*}{-10.9} \\
\hline & His468A(2.24) & & \\
\hline & Ile131A(4.18) & & \\
\hline & Tyr132A(5.39) & & \\
\hline & Leu150A(3.96) & & \\
\hline & Leu204A(4.27) & & \\
\hline & Phe475A(3.96) & & \\
\hline & Ile304A(4.99) & & \\
\hline & Leu139A(4.51) & & \\
\hline \multirow{6}{*}{ 3c. 3} & Met508A(2.38)* & \multirow{6}{*}{2} & \multirow{6}{*}{-10.3} \\
\hline & His377A(3.51)* & & \\
\hline & Ala61A(3.62) & & \\
\hline & Leu376A(4.88) & & \\
\hline & Leu121A(4.84) & & \\
\hline & Tyr118A(3.51) & & \\
\hline \multirow{5}{*}{ 3c. 4} & Phe475A(2.96) & \multirow{5}{*}{0} & \multirow{5}{*}{-7.3} \\
\hline & Ile304A(4.89) & & \\
\hline & Leu139A(3.51) & & \\
\hline & Trp54B(3.58) & & \\
\hline & Ser74A(3.61) & & \\
\hline \multirow{8}{*}{ 3c. 5} & Ser507A(2.78)* & \multirow{8}{*}{1} & \multirow{8}{*}{-10.6} \\
\hline & Met508A(2.19) & & \\
\hline & Tyr118A(3.75) & & \\
\hline & Leu376A(5.45) & & \\
\hline & Leu121A(3.76) & & \\
\hline & Tyr64A(4.78) & & \\
\hline & His377A(4.20) & & \\
\hline & Pro230A(2.20) & & \\
\hline \multirow{7}{*}{ 3c. 6} & Ser507A(3.08)* & \multirow{7}{*}{1} & \multirow{7}{*}{-11} \\
\hline & Met508A(3.25) & & \\
\hline & Leu121A(5.17) & & \\
\hline & Tyr118A(3.92) & & \\
\hline & Leu376A(3.18) & & \\
\hline & His377A(3.25) & & \\
\hline & Pro230A(3.27) & & \\
\hline
\end{tabular}


World Journal of Advanced Research and Reviews, 2021, 12(01), 186-214

\begin{tabular}{|c|c|c|c|}
\hline & Leu87A(4.81) & & \\
\hline & Tyr64A(4.36) & & \\
\hline \multirow{3}{*}{ 3d.1 } & Val324A(1.13) & \multirow{3}{*}{0} & \multirow{3}{*}{-5.5} \\
\hline & Asn305A(4.7) & & \\
\hline & Leu484A(5.84) & & \\
\hline \multirow{3}{*}{$3 \mathrm{~d} .2$} & Leu150A(3.96) & \multirow{3}{*}{0} & \multirow{3}{*}{-1.2} \\
\hline & Leu204A(4.27) & & \\
\hline & Phe475A(3.97) & & \\
\hline \multirow{5}{*}{ 3d.3 } & Asn305A(1.5) & \multirow{5}{*}{0} & \multirow{5}{*}{-10.9} \\
\hline & Tyr304A(2.15) & & \\
\hline & Leu480A(4.35) & & \\
\hline & Met308A(5.09) & & \\
\hline & Tyr476A(5.48) & & \\
\hline \multirow{4}{*}{$3 \mathrm{~d} .4$} & Pro230A(3.26)* & \multirow{4}{*}{1} & \multirow{4}{*}{-13.2} \\
\hline & Leu87A(2.42) & & \\
\hline & Tyr118A(4.36) & & \\
\hline & Leu121A(5.30) & & \\
\hline \multirow{6}{*}{ 3d. 5} & Tyr476A(4.22)* & \multirow{6}{*}{2} & \multirow{6}{*}{-9.9} \\
\hline & Leu484A(3.58)* & & \\
\hline & Tyr304A(3.68) & & \\
\hline & Asn305A(2.58) & & \\
\hline & Glu481A(4.22) & & \\
\hline & Leu480A(2.36) & & \\
\hline \multirow{7}{*}{ 3d.6 } & Leu480A(5.00) & \multirow{7}{*}{2} & \multirow{7}{*}{-10.8} \\
\hline & Tyr476A(2.38)* & & \\
\hline & Pro477A(1.27)* & & \\
\hline & & & \\
\hline & Met308A(4.32) & & \\
\hline & Tyr304A(4.30) & & \\
\hline & Asn305A(1.82) & & \\
\hline
\end{tabular}


Table 3 Ligand-receptor interaction data of Dihydropyridazin-3(2H)-one on PDB ID: 1JXA using PyRx-Virtual Screening Tool

\begin{tabular}{|c|c|c|c|}
\hline Sr. No. & $\begin{array}{l}\text { Interaction of amino acid } \\
\text { having a shortest bond } \\
\text { length( } * \text {-indicates } \mathrm{H} \text {-bond } \\
\text { interacting amino acid) }\end{array}$ & $\begin{array}{l}\text { Number of } \\
\text { hydrogen bond } \\
\text { interactions }\end{array}$ & $\begin{array}{c}\text { Binding affinity } \\
\text { score }\end{array}$ \\
\hline \multirow{6}{*}{ Ciprofloxacin } & $\operatorname{Arg} 22 B(1.73)^{*}$ & \multirow[t]{6}{*}{1} & \multirow[t]{6}{*}{-8.2} \\
\hline & Gly243B(3.26) & & \\
\hline & Tyr251B(4.56) & & \\
\hline & Glu24B(4.73) & & \\
\hline & Glu52B(3.41) & & \\
\hline & $\operatorname{Arg} 21 \mathrm{~B}(3.19)$ & & \\
\hline \multirow{4}{*}{ 3a.1 } & Pro177A(2.45)* & \multirow[t]{4}{*}{1} & \multirow[t]{4}{*}{-10.2} \\
\hline & Val376A(5.10) & & \\
\hline & Phe205A(3.58) & & \\
\hline & Ile234A(4.52) & & \\
\hline \multirow{5}{*}{$3 a .2$} & Leu502A(3.16) & \multirow[t]{5}{*}{0} & \multirow[t]{5}{*}{-11.7} \\
\hline & Leu583A(5.15) & & \\
\hline & Tyr544A(1.38) & & \\
\hline & Ala496A(5.25) & & \\
\hline & Val545A(4.61) & & \\
\hline \multirow{3}{*}{ 3a.3 } & Ala498A(2.26) & \multirow[t]{3}{*}{0} & \multirow[t]{3}{*}{-10.2} \\
\hline & Tyr476A(3.48) & & \\
\hline & Leu480A(3.88) & & \\
\hline \multirow{3}{*}{$3 a .4$} & Glu501A(2.99) & \multirow[t]{3}{*}{0} & \multirow[t]{3}{*}{-9.9} \\
\hline & His504A(4.21) & & \\
\hline & Pro506A(2.87) & & \\
\hline \multirow{3}{*}{$3 a .5$} & Tyr304A(3.15) & \multirow[t]{3}{*}{0} & \multirow[t]{3}{*}{-10} \\
\hline & Leu480A(4.55) & & \\
\hline & Met308A(5.19) & & \\
\hline \multirow{3}{*}{$3 a .6$} & Ile55A(2.42) & \multirow[t]{3}{*}{0} & \multirow[t]{3}{*}{-11} \\
\hline & $\operatorname{Trp54B(4.38)}$ & & \\
\hline & Tyr53A(3.86) & & \\
\hline \multirow{2}{*}{ 3b.1 } & Ile326A(2.88) & \multirow[t]{2}{*}{0} & \multirow[t]{2}{*}{-11.1} \\
\hline & Glu325A(3.51) & & \\
\hline \multirow[b]{2}{*}{$3 b .2$} & Leu468A(2.22) & \multirow[t]{2}{*}{0} & \multirow[t]{2}{*}{-9.4} \\
\hline & $\begin{array}{l}\text { Leu502A(3.21) } \\
\text { Ile561A(2.66) }\end{array}$ & & \\
\hline
\end{tabular}


World Journal of Advanced Research and Reviews, 2021, 12(01), 186-214

\begin{tabular}{|c|c|c|c|}
\hline \multirow{3}{*}{$3 b .3$} & $\operatorname{Arg} 472 \mathrm{~A}(2.98)$ & \multirow[t]{3}{*}{0} & \multirow[t]{3}{*}{-8.1} \\
\hline & Ala498A(3.11) & & \\
\hline & Tyr476A(2.55) & & \\
\hline \multirow{3}{*}{ 3b.4 } & Tyr118A(3.72) & \multirow[t]{3}{*}{0} & \multirow[t]{3}{*}{-9.1} \\
\hline & Pro230A(3.55) & & \\
\hline & Leu87A(4.19) & & \\
\hline \multirow{5}{*}{ 3b.5 } & Leu376A(3.11) & \multirow[t]{5}{*}{0} & \multirow[t]{5}{*}{-10.9} \\
\hline & His377A(3.22) & & \\
\hline & Tyr476A(3.88) & & \\
\hline & Leu480A(4.58) & & \\
\hline & Glu325A(3.59) & & \\
\hline \multirow{2}{*}{$3 \mathrm{~b} .6$} & Leu139A(2.51) & \multirow[t]{2}{*}{0} & \multirow[t]{2}{*}{-8.7} \\
\hline & Trp54B(2.58) & & \\
\hline \multirow{3}{*}{ 3c.1 } & Ile326A(2.98) & \multirow[t]{3}{*}{0} & \multirow[t]{3}{*}{-10.1} \\
\hline & Met308A(3.88) & & \\
\hline & Tyr304A(2.98) & & \\
\hline \multirow{4}{*}{$3 c .2$} & Leu480A(4.58) & \multirow[t]{4}{*}{0} & \multirow[t]{4}{*}{-8.7} \\
\hline & Glu325A(3.39) & & \\
\hline & $\operatorname{Arg} 472 \mathrm{~A}(2.88)$ & & \\
\hline & Ala498A(3.21) & & \\
\hline \multirow{4}{*}{ 3c. 3} & Tyr497A(1.50) & \multirow[t]{4}{*}{0} & \multirow[t]{4}{*}{-10.4} \\
\hline & Pro506A(1.35) & & \\
\hline & Tyr304A(1.10) & & \\
\hline & Ile326A(2.35) & & \\
\hline \multirow{5}{*}{$3 c .4$} & Leu376A(3.45) & \multirow[t]{5}{*}{0} & \multirow[t]{5}{*}{-8} \\
\hline & Leu121A(2.76) & & \\
\hline & Tyr64A(4.28) & & \\
\hline & His377 A(4.29) & & \\
\hline & Pro230A(2.21) & & \\
\hline \multirow{4}{*}{$3 c .5$} & Tyr304A(4.51) & \multirow[t]{4}{*}{0} & \multirow[t]{4}{*}{-10.2} \\
\hline & Ile326A(4.25) & & \\
\hline & Tyr497A(4.18) & & \\
\hline & Pro506A(5.47) & & \\
\hline \multirow{4}{*}{ 3c. 6} & Glu495A(2.56) & \multirow[t]{4}{*}{0} & -9.6 \\
\hline & Tyr497A(2.36) & & \\
\hline & (011509A(2 36) & & \\
\hline & Leub09A(2.36) & & \\
\hline
\end{tabular}


World Journal of Advanced Research and Reviews, 2021, 12(01), 186-214

\begin{tabular}{|c|c|c|c|}
\hline \multirow{7}{*}{$3 \mathrm{~d} .1$} & Val324A(4.35) & \multirow[t]{7}{*}{0} & \multirow[t]{7}{*}{-10} \\
\hline & Tyr304A(4.31) & & \\
\hline & Leu480A(4.23) & & \\
\hline & $\operatorname{Met} 308 \mathrm{~A}(4.21)$ & & \\
\hline & Tyr476A(3.55) & & \\
\hline & Asn305A(3.38) & & \\
\hline & Leu484A(2.36) & & \\
\hline \multirow{3}{*}{$3 \mathrm{~d} .2$} & His377A(3.72) & \multirow[t]{3}{*}{0} & \multirow[t]{3}{*}{-1.1} \\
\hline & Tyr476A(3.98) & & \\
\hline & Leu480A(4.28) & & \\
\hline \multirow{5}{*}{$3 \mathrm{~d} .3$} & Asn305A(2.26) & \multirow[t]{5}{*}{0} & \multirow[t]{5}{*}{-11.9} \\
\hline & Tyr304A(3.87) & & \\
\hline & Tyr476A(3.62) & & \\
\hline & Met308A(2.69) & & \\
\hline & Leu480A(2.66) & & \\
\hline \multirow{5}{*}{ 3d. 4} & Phe58A(5.26) & \multirow[t]{5}{*}{0} & \multirow[t]{5}{*}{-10.8} \\
\hline & Ile55A(5.42) & & \\
\hline & $\operatorname{Trp54B(4.38)}$ & & \\
\hline & Tyr53A(2.86) & & \\
\hline & $\operatorname{Trp54A(4.42)}$ & & \\
\hline \multirow{6}{*}{ 3d. 5} & Leu484A(2.26) & \multirow[t]{6}{*}{0} & \multirow[t]{6}{*}{-10.5} \\
\hline & Tyr476A(3.62) & & \\
\hline & Asn305A(2.65) & & \\
\hline & Glu481A(3.21) & & \\
\hline & Leu480A(1.99) & & \\
\hline & Tyr304A(3.36) & & \\
\hline \multirow{6}{*}{3 d. 6} & Ile326A(3.99) & \multirow[t]{6}{*}{0} & \multirow[t]{6}{*}{-10.9} \\
\hline & Tyr304A(3.65) & & \\
\hline & Asn305A(2.98) & & \\
\hline & Met308A(3.58) & & \\
\hline & Pro477A(2.46) & & \\
\hline & Tyr476A(2.29) & & \\
\hline
\end{tabular}


Table 4 Ligand-receptor interaction data of Dihydropyridazin-3(2H)-one on PDB ID: 10J0 using PyRx-Virtual Screening Tool

\begin{tabular}{|c|c|c|c|}
\hline Sr. No. & $\begin{array}{l}\text { Interaction of amino acid having a } \\
\text { shortest bond length }(* \text {-indicates } \\
\text { H-bond interacting amino acid) }\end{array}$ & $\begin{array}{l}\text { Number of } \\
\text { hydrogen bond } \\
\text { interactions }\end{array}$ & $\begin{array}{c}\text { Binding affinity } \\
\text { score }\end{array}$ \\
\hline \multirow[t]{6}{*}{ Albendazole } & Ala283A(2.70)* & \multirow{6}{*}{4} & \multirow{6}{*}{-6.3} \\
\hline & Glu288A(2.55)* & & \\
\hline & $\mathrm{Gln} 291 \mathrm{~A}(2.34)^{*}$ & & \\
\hline & $\mathrm{Gln} 279 \mathrm{~A}(2.28)^{*}$ & & \\
\hline & Ser274A(1.31) & & \\
\hline & Leu284A(3.98) & & \\
\hline \multirow[t]{6}{*}{ 3a.1 } & Arg359A(3.86) & \multirow{6}{*}{1} & \multirow{6}{*}{-10.7} \\
\hline & Pro358A(4.71) & & \\
\hline & Leu361A(4.38) & & \\
\hline & His227 A(3.57) & & \\
\hline & Val231A(2.49) & & \\
\hline & Glu27A(4.79)* & & \\
\hline \multirow[t]{9}{*}{ 3a.2 } & Ser188A(3.58) & \multirow{9}{*}{0} & \multirow{9}{*}{-10.7} \\
\hline & Trp101A(2.99) & & \\
\hline & His190A(2.89) & & \\
\hline & Ala411A(4.78) & & \\
\hline & Glu407A(2.58) & & \\
\hline & Thr409A(3.64) & & \\
\hline & Phe408A(2.98) & & \\
\hline & Glu412A(3.65) & & \\
\hline & Phe385A(2.26) & & \\
\hline \multirow[t]{12}{*}{ 3a.3 } & Ser138A(2.26) & \multirow{12}{*}{1} & \multirow{12}{*}{-9.4} \\
\hline & Pro171A(2.51) & & \\
\hline & His137A(3.98) & & \\
\hline & Leu192A(4.23) & & \\
\hline & His190A(4.56) & & \\
\hline & Asn195A(4.29)* & & \\
\hline & $\mathrm{Gln} 191 \mathrm{~A}(4.78)$ & & \\
\hline & Ile152A(4.25) & & \\
\hline & Ser188A(2.99) & & \\
\hline & Val189A(4.76) & & \\
\hline & Val170A(4.25) & & \\
\hline & $\begin{array}{l}\text { Val169A(5.25) } \\
\text { Leu139A(3.69) }\end{array}$ & & \\
\hline
\end{tabular}


World Journal of Advanced Research and Reviews, 2021, 12(01), 186-214

\begin{tabular}{|c|c|c|c|}
\hline \multirow[t]{5}{*}{ 3a.4 } & Tyr64A(3.28) & \multirow{5}{*}{0} & \multirow{5}{*}{-9.3} \\
\hline & His377A(4.29) & & \\
\hline & Pro230A(2.21) & & \\
\hline & Glu407A(1.58) & & \\
\hline & Thr409A(3.64) & & \\
\hline \multirow[t]{11}{*}{ 3а. 5} & Ala153A & \multirow{11}{*}{0} & \multirow{11}{*}{-8.9} \\
\hline & Leu192A & & \\
\hline & Ile152A & & \\
\hline & Asn195A & & \\
\hline & Gln191A & & \\
\hline & Ala153A & & \\
\hline & Thr149A & & \\
\hline & Ser138A & & \\
\hline & Gly144A & & \\
\hline & Ser145A & & \\
\hline & His137A & & \\
\hline \multirow[t]{5}{*}{ 3а. 6} & Arg359A(5.42) & \multirow{5}{*}{1} & \multirow{5}{*}{-9.4} \\
\hline & $\operatorname{Arg} 318 \mathrm{~A}(2.11)^{*}$ & & \\
\hline & Val231A(5.39) & & \\
\hline & Val23A(4.43) & & \\
\hline & His227A(4.39) & & \\
\hline \multirow[t]{10}{*}{$3 \mathrm{~b} .1$} & Ser166A(2.68)* & \multirow{10}{*}{1} & \multirow{10}{*}{-10.6} \\
\hline & Glu198A(3.65) & & \\
\hline & Ile163A(2.86) & & \\
\hline & Met164A(3.67) & & \\
\hline & Asp197A(4.22) & & \\
\hline & Thr196A(2.99) & & \\
\hline & Ile152A(3.65) & & \\
\hline & Asn195A(4.23) & & \\
\hline & $\operatorname{Arg} 156 \mathrm{~A}(3.65)$ & & \\
\hline & Ala153A(4.93) & & \\
\hline \multirow[t]{6}{*}{$3 \mathrm{~b} .2$} & Glu405A(5.23) & \multirow{6}{*}{0} & \multirow{6}{*}{-9.9} \\
\hline & Met406A(4.26) & & \\
\hline & Glu410A(4.22) & & \\
\hline & Thr409A(3.44) & & \\
\hline & Phe389A(3.89) & & \\
\hline & Glu412A(3.67) & & \\
\hline
\end{tabular}


World Journal of Advanced Research and Reviews, 2021, 12(01), 186-214

\begin{tabular}{|c|c|c|c|}
\hline & Leu187A(3.68) & & \\
\hline & Trp101A(3.56) & & \\
\hline & Ala411A(5.23) & & \\
\hline & Phe408A(2.36) & & \\
\hline \multirow[t]{10}{*}{$3 \mathrm{~b} .3$} & Thr196A(4.23) & \multirow{10}{*}{0} & \multirow{10}{*}{-9} \\
\hline & Pro171A(2.23) & & \\
\hline & Val169A(2.63) & & \\
\hline & Val170A(4.26) & & \\
\hline & Leu139A(3.69) & & \\
\hline & His137A(3.65) & & \\
\hline & Leu192A(2.26) & & \\
\hline & Ser188A(3.65) & & \\
\hline & Ile152A(4.28) & & \\
\hline & Gln191A(3.65) & & \\
\hline \multirow[t]{5}{*}{ 3b. 4} & Thr409A(3.24) & \multirow{5}{*}{0} & \multirow{5}{*}{-9.3} \\
\hline & Phe389A(3.89) & & \\
\hline & Glu412A(3.58) & & \\
\hline & Leu187A(3.10) & & \\
\hline & Trp101A(3.56) & & \\
\hline \multirow[t]{11}{*}{$3 \mathrm{~b} .5$} & Ser166A(2.16)* & \multirow{11}{*}{3} & \multirow{11}{*}{-8.4} \\
\hline & Thr199A(2.61)* & & \\
\hline & Leu192A(3.06)* & & \\
\hline & Arg156A(3.88) & & \\
\hline & Ala153A(4.22) & & \\
\hline & $\begin{array}{l}\text { Asn195A(4.23) } \\
\text { Jle152A(3.89) }\end{array}$ & & \\
\hline & Thr196A(2.98) & & \\
\hline & Asp197A(5.23) & & \\
\hline & Met164A(4.23) & & \\
\hline & Ser165A(3.98) & & \\
\hline & $\begin{array}{l}\text { Gln198A(3.56) } \\
\text { Leu263A(2.36) }\end{array}$ & & \\
\hline \multirow[t]{5}{*}{$3 \mathrm{~b} .6$} & Leu192A(3.56)* & \multirow{5}{*}{1} & \multirow{5}{*}{-9.6} \\
\hline & Asn195A(3.69) & & \\
\hline & Thr196A(3.56) & & \\
\hline & Ile152A(4.26) & & \\
\hline & Ala153A(4.36) & & \\
\hline
\end{tabular}


World Journal of Advanced Research and Reviews, 2021, 12(01), 186-214

\begin{tabular}{|c|c|c|c|}
\hline & Lys154A(4.23) & & \\
\hline & Glu157A(2.63) & & \\
\hline & $\operatorname{Arg} 156 \mathrm{~A}(2.59)$ & & \\
\hline \multirow[t]{10}{*}{ 3c. 1} & Met164A(3.65) & \multirow{10}{*}{0} & \multirow{10}{*}{-9.7} \\
\hline & Leu263A(3.66) & & \\
\hline & Ala153A(4.25) & & \\
\hline & Thr149A(2.36) & & \\
\hline & Gln191A(3.56) & & \\
\hline & Ile152A(3.55) & & \\
\hline & Asn195A(3.89) & & \\
\hline & Thr196A(4.26) & & \\
\hline & Glu194A(4.36) & & \\
\hline & $\operatorname{Arg} 156 \mathrm{~A}(4.32)$ & & \\
\hline \multirow[t]{11}{*}{$3 c .2$} & Met403A(3.87) & \multirow{11}{*}{0} & \multirow{11}{*}{-9} \\
\hline & Tyr106A(3.89) & & \\
\hline & Glu407A(3.28) & & \\
\hline & Glu191A(4.28) & & \\
\hline & Trp101A(4.26) & & \\
\hline & Ser188A(4.89) & & \\
\hline & Asn184A(4.55) & & \\
\hline & Leu187A(4.29) & & \\
\hline & Glu410A(4.26) & & \\
\hline & His190A(3.85) & & \\
\hline & Ala411A(3.65) & & \\
\hline \multirow[t]{9}{*}{ 3c. 3} & Met164A(3.65) & \multirow{9}{*}{0} & \multirow{9}{*}{-8.6} \\
\hline & Thr96A(2.99) & & \\
\hline & $\operatorname{Arg} 156 \mathrm{~A}(2.96)$ & & \\
\hline & Glu191A(5.63) & & \\
\hline & $\begin{array}{l}\text { Ala153A(5.08) } \\
\text { Glv146A(4.29) }\end{array}$ & & \\
\hline & Ser145A(5.36) & & \\
\hline & Gly146(5.26) & & \\
\hline & His105(4.25) & & \\
\hline & Leu150(4.26) & & \\
\hline \multirow[t]{2}{*}{ 3c. 4} & Glu191A(3.18) & \multirow{2}{*}{0} & \multirow{2}{*}{-6.8} \\
\hline & $\operatorname{Trp} 101 \mathrm{~A}(3.16)$ & & \\
\hline
\end{tabular}


World Journal of Advanced Research and Reviews, 2021, 12(01), 186-214

\begin{tabular}{|c|c|c|c|}
\hline & Ser188A(3.80) & & \\
\hline & Asn184A(4.50) & & \\
\hline & Ala153A(4.26) & & \\
\hline & Gly146A(4.21) & & \\
\hline & Ser145A(5.36) & & \\
\hline \multirow[t]{14}{*}{$3 c .5$} & His105A(4.86)* & \multirow{14}{*}{1} & \multirow{14}{*}{-8} \\
\hline & Leu151A(3.98) & & \\
\hline & Ala153A(4.23) & & \\
\hline & Ser145A(3.98) & & \\
\hline & Met164A(3.69) & & \\
\hline & $\operatorname{Arg} 156 \mathrm{~A}(4.23)$ & & \\
\hline & Thr196A(3.69) & & \\
\hline & Asn195A(5.32) & & \\
\hline & Ile152A(5.32) & & \\
\hline & Thr149A(3.65) & & \\
\hline & Gly148A(4.56) & & \\
\hline & Leu150A(3.98) & & \\
\hline & Met147A(4.56) & & \\
\hline & $\mathrm{Gln} 191 \mathrm{~A}(4.32)$ & & \\
\hline \multirow[t]{8}{*}{$3 c .6$} & Asp197A(5.23) & \multirow{8}{*}{0} & \multirow{8}{*}{-8.4} \\
\hline & Met164A(4.23) & & \\
\hline & Ser165A(3.98) & & \\
\hline & Gln198A(3.56) & & \\
\hline & Ser145A(3.98) & & \\
\hline & Met164A(3.69) & & \\
\hline & $\operatorname{Arg} 156 \mathrm{~A}(4.23)$ & & \\
\hline & Thr196A(3.69) & & \\
\hline \multirow[t]{10}{*}{ 3d.1 } & Arg156A(3.63) & \multirow{10}{*}{0} & \multirow{10}{*}{-10.8} \\
\hline & Ile155A(4.26) & & \\
\hline & Met164A(3.67) & & \\
\hline & Ile152A(3.65) & & \\
\hline & Ala153A(3.56) & & \\
\hline & Thr196A(3.69) & & \\
\hline & Glu191A(4.26) & & \\
\hline & Asn195A(4.23) & & \\
\hline & Leu192A(4.25) & & \\
\hline & Val193A(4.21) & & \\
\hline
\end{tabular}


World Journal of Advanced Research and Reviews, 2021, 12(01), 186-214

\begin{tabular}{|c|c|c|c|}
\hline & $\operatorname{Arg} 262 \mathrm{~A}(4.02)$ & & \\
\hline & Pro261A(3.89) & & \\
\hline \multirow[t]{5}{*}{$3 \mathrm{~d} .2$} & His377A(4.72) & \multirow{5}{*}{0} & \multirow{5}{*}{-1.2} \\
\hline & Tyr476A(3.56) & & \\
\hline & Asn195A(4.21) & & \\
\hline & Leu192A(4.24) & & \\
\hline & Val193A(4.22) & & \\
\hline \multirow[t]{12}{*}{$3 \mathrm{~d} .3$} & Leu150A(3.27) & \multirow{12}{*}{1} & \multirow{12}{*}{-9.3} \\
\hline & Leu135A(3.98) & & \\
\hline & Ile155A(3.58) & & \\
\hline & Met164A(4.63) & & \\
\hline & His264A(4.65)* & & \\
\hline & Leu151A(3.99) & & \\
\hline & Ala153A(4.29) & & \\
\hline & Ile152A(4.22) & & \\
\hline & Glu194A(4.23) & & \\
\hline & $\operatorname{Arg} 262 \mathrm{~A}(4.26)$ & & \\
\hline & Val193A(3.56) & & \\
\hline & Asn195A(3.65) & & \\
\hline \multirow[t]{6}{*}{ 3d.4 } & Glu191A(3.38) & \multirow{6}{*}{0} & \multirow{6}{*}{-10.7} \\
\hline & Asn195A(4.23) & & \\
\hline & Leu192A(4.25) & & \\
\hline & Arg262A(4.26) & & \\
\hline & Val193A(3.56) & & \\
\hline & His264A(4.35) & & \\
\hline \multirow[t]{8}{*}{$3 \mathrm{~d} .5$} & Arg262A(4.58) & \multirow{8}{*}{0} & \multirow{8}{*}{-9} \\
\hline & Glu191A(5.20) & & \\
\hline & $\operatorname{Arg} 156 \mathrm{~A}(4.96)$ & & \\
\hline & Asn195A(4.86) & & \\
\hline & Thr196A(3.65) & & \\
\hline & Glu194A(4.89) & & \\
\hline & Ile152A(3.69) & & \\
\hline & Leu192A(3.35) & & \\
\hline \multirow[t]{4}{*}{ 3d.6 } & Ala153A(4.86)* & \multirow{4}{*}{2} & \multirow{4}{*}{-9.5} \\
\hline & $\operatorname{Arg} 156 \mathrm{~A}(3.23)$ & & \\
\hline & Thr196A(4.23) & & \\
\hline & Leu135A(3.65) & & \\
\hline
\end{tabular}




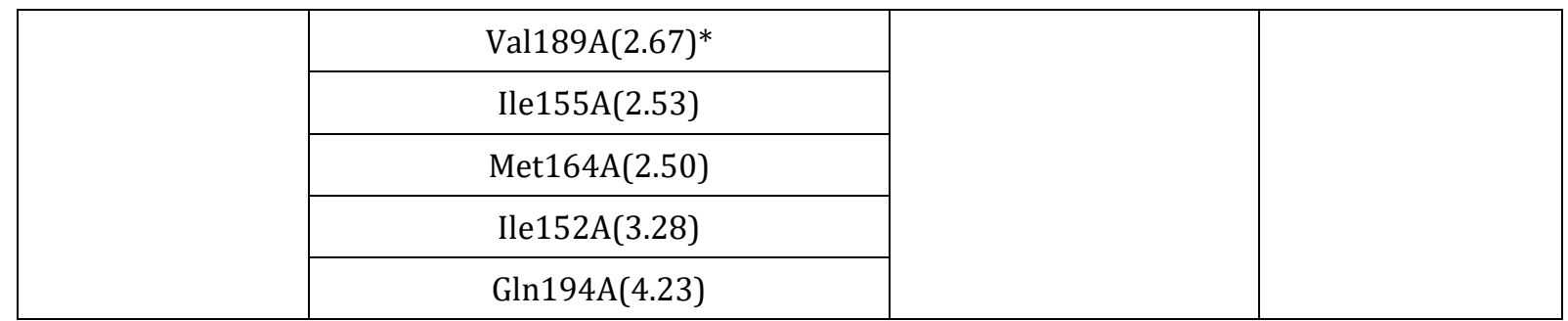

\subsection{Discussion of Antifungal series}
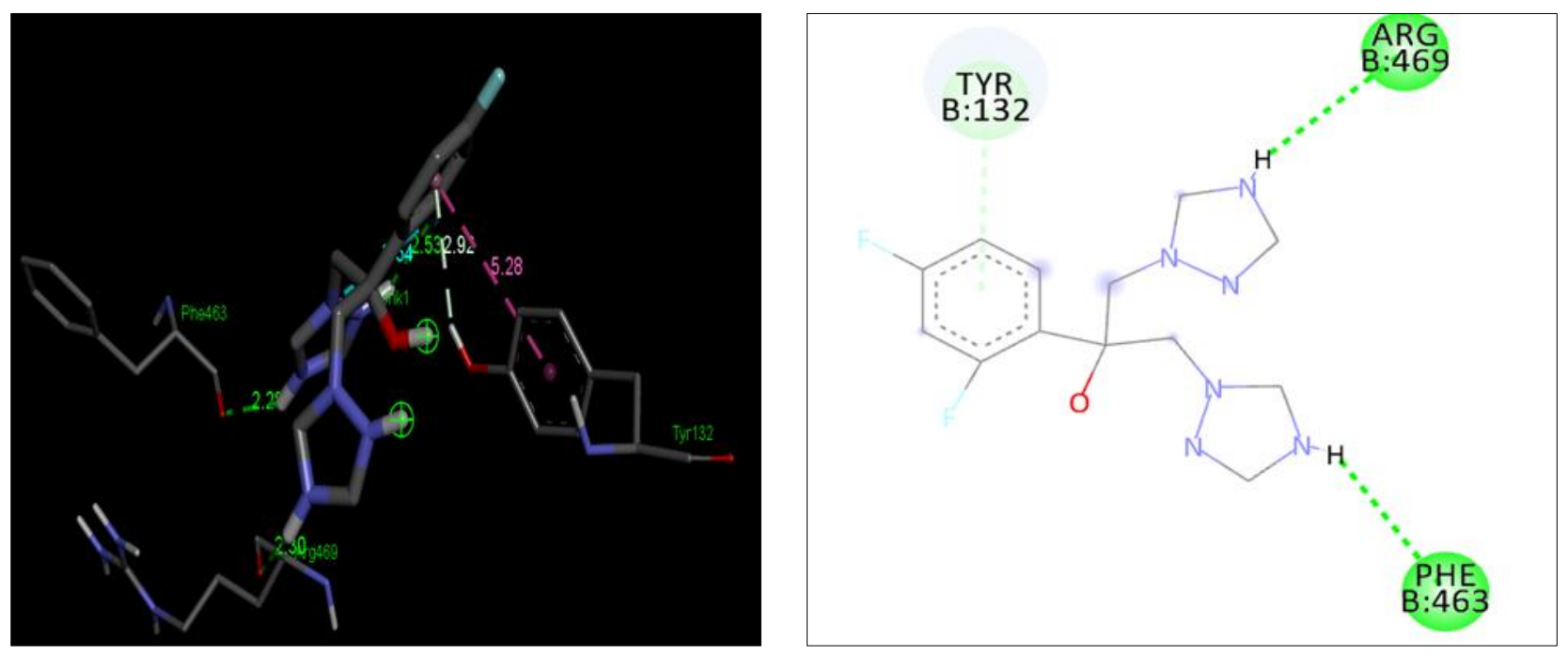

Figure 5 Interaction of Fluconazole with amino acids Tyr132B(2.92) ; $\operatorname{Arg} 469 B(2.30)^{*}$ Phe463B(2.28)*

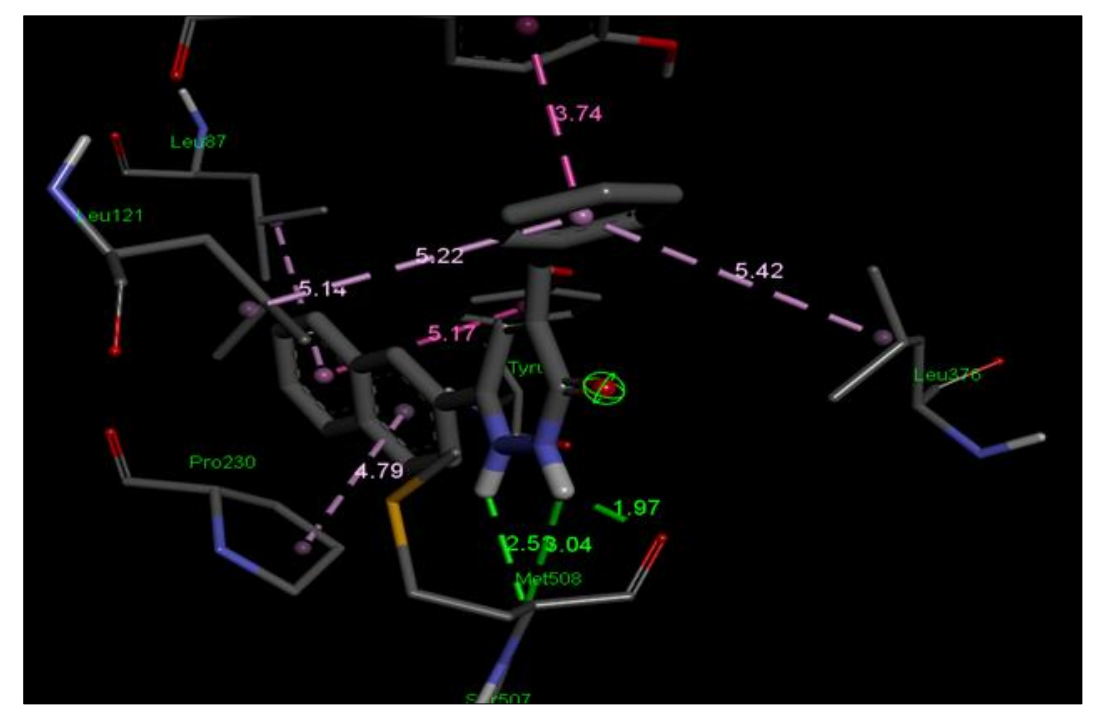

Figure 6 Interaction of $3 \mathrm{a} 5$ with amino acids Ser507A(3.04)* ; Met508A(2.53)*; Leu376A(5.42) ; Leu121A(5.14) ; Tyr118A(3.74) ; Leu87A(5.22) ; Tyr64A(5.17) ; Pro230A(4.79) 


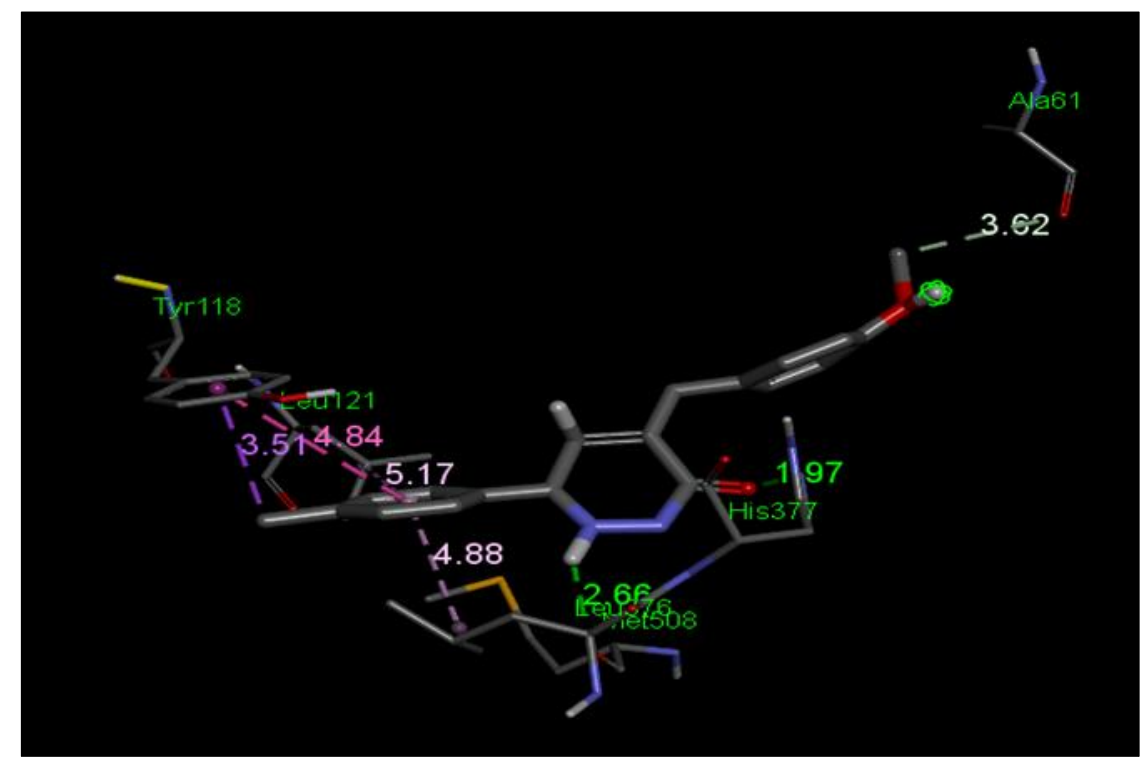

Figure 7 Interaction of 3c3 with amino acids Met508A(2.38)*; His377A(3.51)*; Ala61A(3.62) ; Leu376A(4.88) ; Leu121A(4.84) ; Tyr118A(3.51)

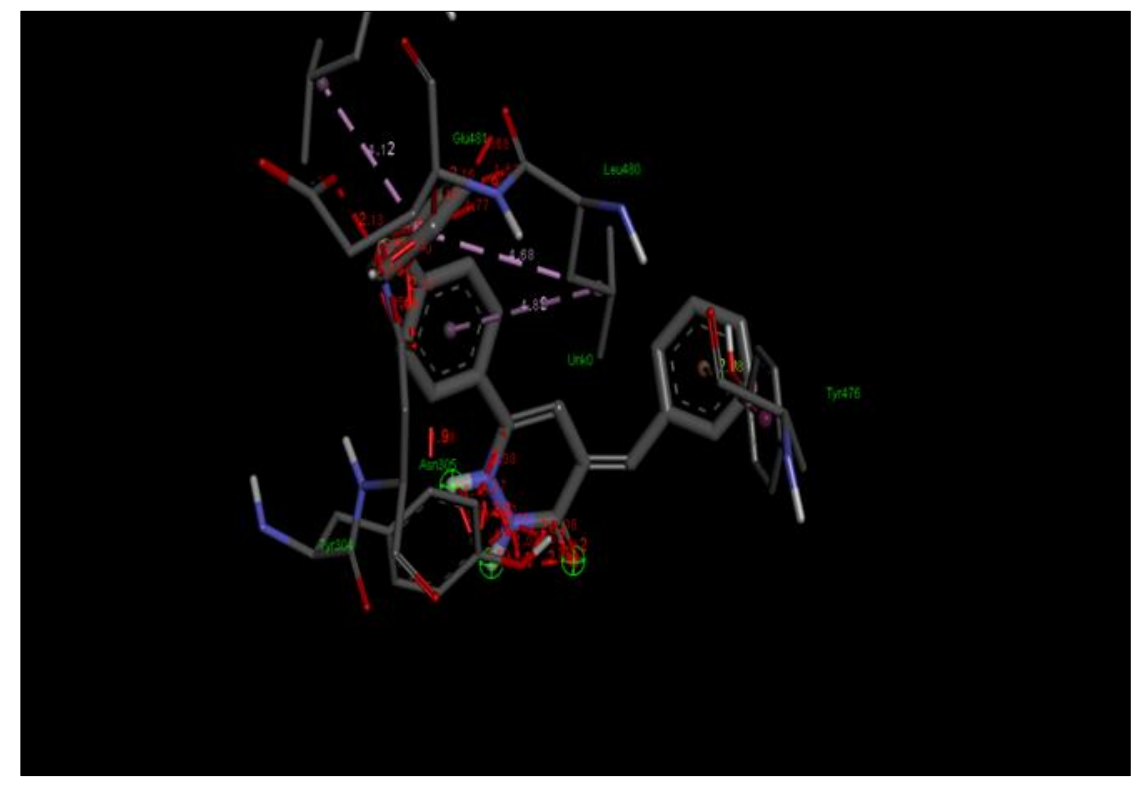

Figure 8 Interaction of $3 \mathrm{~d} 5$ with amino acids Tyr476A(4.22)* Leu484A(3.58)* Tyr304A(3.68) Asn305A(2.58) ; Glu481A(4.22) ; Leu480A(2.36) 


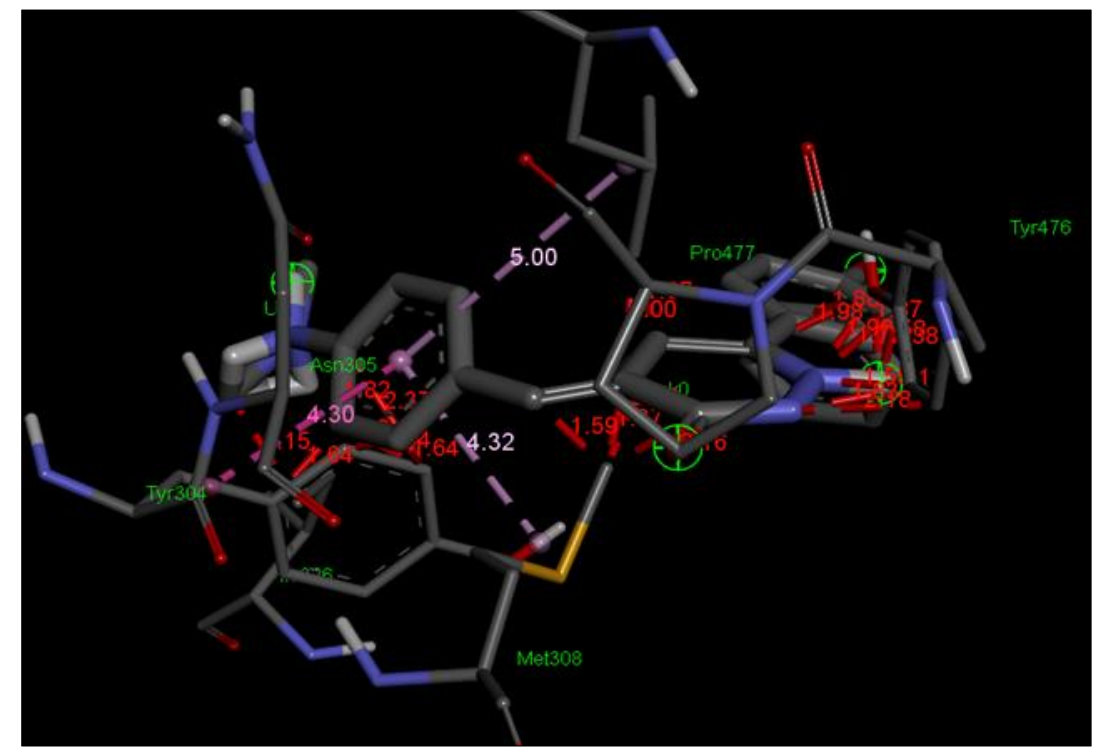

Figure 9 Interaction of $3 \mathrm{~d} 6$ with amino acids Leu480A(5.00) ; Tyr476A(2.38)* Pro477A(1.27)* $\operatorname{Met308A(4.32)~;~}$ Tyr304A(4.30) ; Asn305A(1.82)

\subsection{Discussion of Antibacterial series}
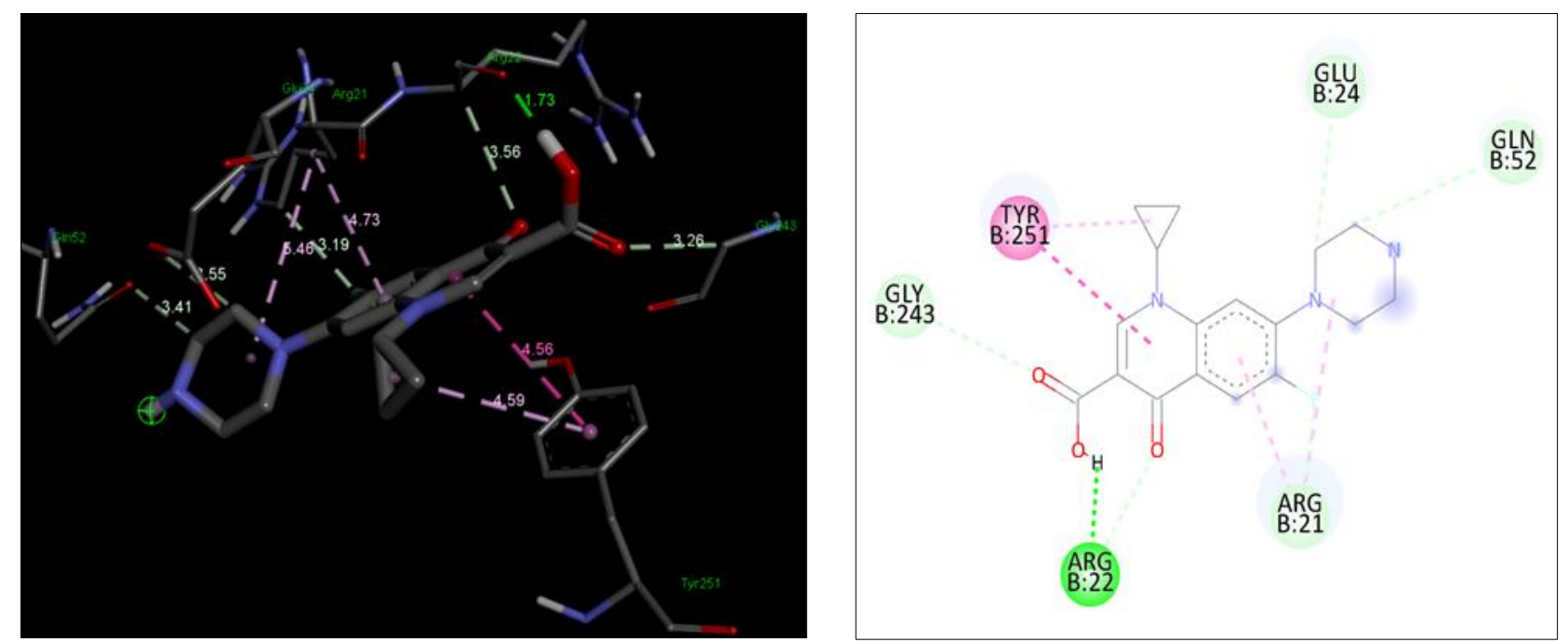

Figure 10 Interaction of Ciprofloxacin with amino acids $\operatorname{Arg} 22 \mathrm{~B}(1.73) *$; Gly243B(3.26) ; Tyr251B(4.56) ; Glu24B(4.73) ; Glu52B(3.41) ; Arg21B(3.19) 


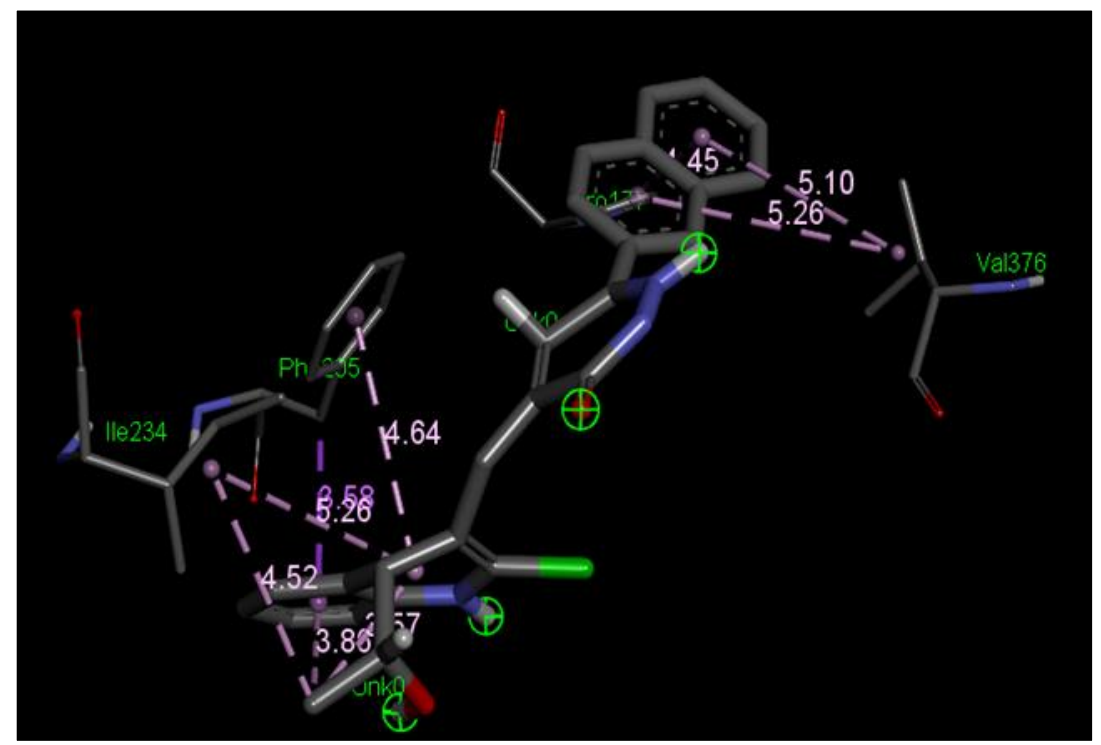

Figure 11 Interaction of 3a1 with amino acids Pro177A(2.45)*; Val376A(5.10) ; Phe205A(3.58) ; Ile234A(4.52)

\subsection{Discussion of Antihelmintic series}
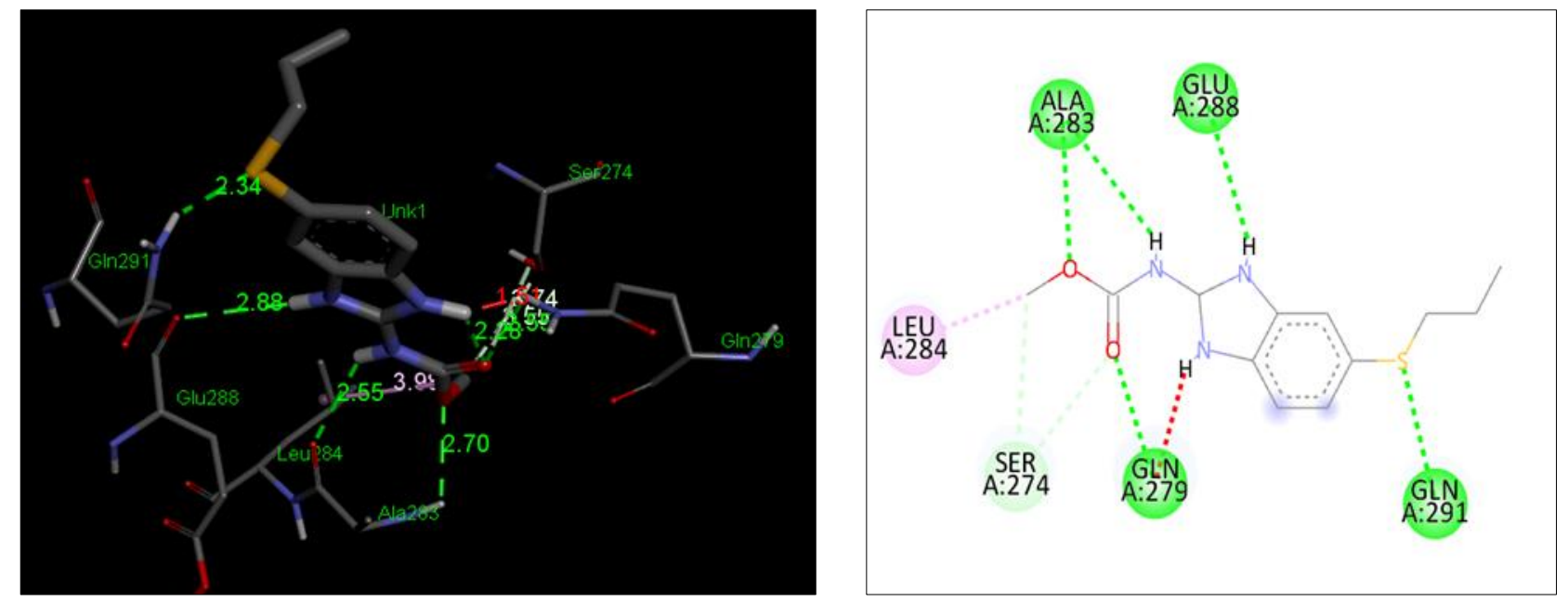

Figure 12 Interaction of Albendazole with amino acids Ala283A(2.70)*; Glu288A(2.55)*; Gln291A(2.34)*; Gln279A(2.28)*; Ser274A(1.31) ; Leu284A(3.98) 


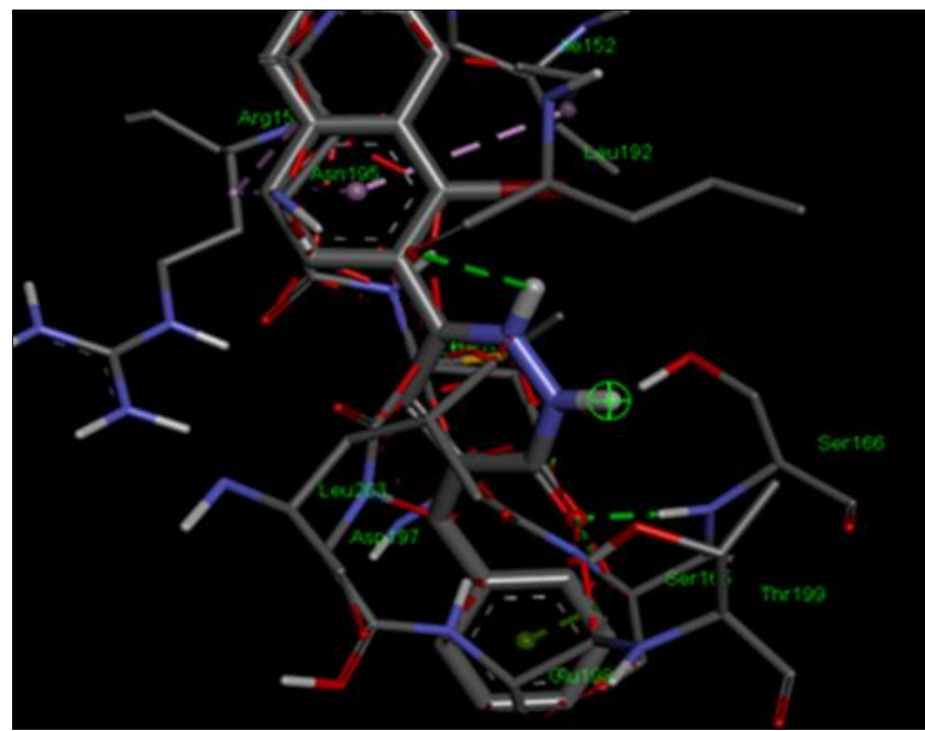

Figure 13 Interaction of $3 b 5$ with amino acids Ser166A(2.16)*; Thr199A(2.61)* ; Leu192A(3.06)*;Arg156A(3.88) ; Ala153A(4.22) ; Asn195A(4.23) ; Ile152A(3.89) ; Thr196A(2.98) ; Asp197A(5.23) ; Met164A(4.23) ; Ser165A(3.98) ; Gln198A(3.56) ; Leu263A(2.36)

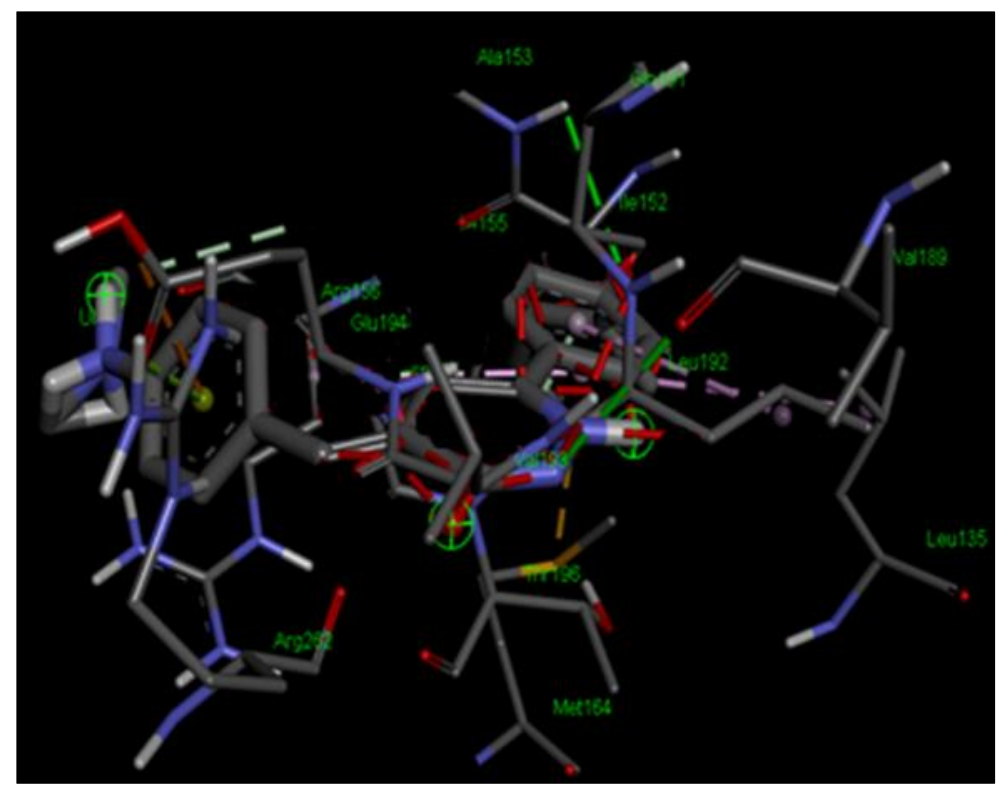

Figure 14 Interaction of $3 \mathrm{~d} 6$ with amino acids Ala153A(4.86)* $\operatorname{Arg} 156 \mathrm{~A}(3.23)$; Thr196A(4.23) ; Leu135A(3.65) ; Val189A(2.67)* ; Ile155A(2.53) ; Met164A(2.50) ; Ile152A(3.28) ; Gln194A(4.23)

\section{Result and discussion of all series}

The output of molecular docking is related to protein-ligand interaction. The outcome of protein-ligand interaction along with standard drug has been summed up in tabular form as Binding affinity score, and no. of $\mathrm{H}$ - bondings and amino acid interactions. The negative binding energies of the ligand indicate stable binding interaction between receptor and ligands.

The current study includes docking of 24 compounds using PDB(5TZ1) with Fluconazole as a Standard drug, PDB(1JXA) with Ciprofloxacin as a Standard drug, PDB(10J0) with Albendazole as a Standard drug. In the case of Antifungals, all the test compounds showed better Binding affinity scores (except $3 \mathrm{~d} 1$ and $3 \mathrm{~d} 2$ ) as compared to standard drugs, In the case of Antibacterials, all the test compounds showed better Binding affinity scores (except 3b3, 3c4, and3d2) as 
compared to standard drug. In the case of Antihelmintics, all the test compounds showed a better Binding affinity score (except $3 \mathrm{~d} 2$ ) as compared to standard drugs. Based on H-bond interactions of these 24 compounds, Compound $3 \mathrm{a} 5,3 \mathrm{c} 3,3 \mathrm{~d} 5$, $3 \mathrm{~d} 6$ for antifungal; Compound 3a1 for antibacterial; Compound 3b5,3d6 were found to be the potent outcome for antihelmintic activity.

The results obtained demonstrated that all examined ligands have comparable orientation and position inside the putative binding site of the above-mentioned proteins which serves as a passage channel for the substrate to the active site. There is a strong connection between the affinity of the ligand towards protein and binding free energy which can contribute to understanding and interpreting the activity of ligand by various possible mechanisms.Also, the geometry of the ligand-receptor complex assumes a fundamental part in forming drug activity. This insilico study also provides a great idea to the researchers looking for novel acting agents for antifungal, antibacterial, and antihelmintic action.It may be well suggested that the above-mentioned proteins might be tightly engaged with pyridazinone analogs bearing benzylidene substituents and aromatic ring accordingly and based on data, the ultimate compounds are needed to be synthesized for further exploration.

\section{Conclusion}

The current study examines the structural and binding features of protein using diverse chemical structures. The core information about the group involved in binding into that particular protein is uncovered by computational docking of 3D structures with high precision and functional characterization. The interaction between the protein and the ligand specifically target the functional residues of active site and put them in a suitable docking position with the least binding energy. Furthermore, the experimental data might aid in the analysis of effective and reliable functional characterization of these ligands. Thus, computational screening for a novel agent followed by in vitro assessment might be beneficial in developing commercial formulations, either alone or in combination with other, or utilized with other integrated techniques for improved management of fungal, bacterial, and helmintic diseases.

\section{Compliance with ethical standards}

\section{Acknowledgments}

We express our sincere thanks toDr. Sukhbirlal khokra and Director of the Institute of Pharmaceutical Sciences, Kurukshetra University, Kurukshetra for providing necessary research facilities.

\section{Disclosure of conflict of interest}

There are no conflicts of interest declared by the authors.

\section{References}

[1] N Berdigaliyev, M Aljofan. An overview of drug discovery and development, Future Med. Chem. 2020; 12(10): 939-947.

[2] AK Ghose, VN Viswanadhan, JJ Wendoloski. A knowledge-based approach in designing combinatorial or medicinal chemistry libraries for drug discovery. 1. A qualitative and quantitative characterization of known drug databases," J. Comb. Chem.1999; 1(1): 55-68.

[3] G Sliwoski, S Kothiwale, J Meiler, EW Lowe. Computational methods in drug discovery, Pharmacol. Rev. 2014; 66(1): 334-395.

[4] XY Meng, HX Zhang, M Mezei, M Cui. Molecular Docking: A Powerful Approach for Structure-Based Drug Discovery, Curr. Comput. Aided-Drug Des. 2011; 7(2): 146-157.

[5] L Ferreira, R dos Santos, G Oliva, A Andricopulo. Molecular Docking and Structure-Based Drug Design Strategies, Molecules. 2015; 20(7): 13384-13421.

[6] SS Azam, SW Abbasi. Molecular docking studies for the identification of novel melatoninergic inhibitors for acetylserotonin-0-methyltransferase using different docking routines, Theor. Biol. Med. Model. $2013 ; 10$ (1): 63.

[7] Y Haddad, V Adam, Z Heger. Ten quick tips for homology modeling of high-resolution protein 3D structures, PLOS Comput. Biol. 2020; 16(4): p.e1007449. 
[8] E Lionta G Spyrou, DK Vassilatis, Z Cournia. Structure-based virtual screening for drug discovery: principles, applications, and recent advances, Curr. Top. Med. Chem. 2014; 14(16): 1923-1938.

[9] DA Silva, GR Bowman, A Sosa-Peinado, X Huang. A Role for Both Conformational Selection and Induced Fit in Ligand Binding by the LAO Protein, PLoS Comput. Biol. 2011; 7(5): p.e1002054.

[10] TA, B Va. Molecular Docking: From Lock and Key to Combination Lock, J. Mol. Med. Clin. Appl. 2018;2(1): 106109.

[11] DM Lorber, BK Shoichet. Flexible ligand docking using conformational ensembles: Flexible ligand docking, Protein Sci. 1998; 7(4): 938-950.

[12] S Agarwal, R Mehrotra. An overview of Molecular Docking, JSM chem. 2016; 4(2): 5.

[13] M Asif. Various Chemical and Biological Activities of Pyridazinone Derivatives, Central European Journal of Experimental Biology. 2017; 1: 19.

[14] SK Verma, R Irrchhaiya, KP Namdeo, VK Singh, S Khurana, A Singh. Synthesis and antimicrobial activity of some pyridazinone derivatives, Biomedical and Pharmacology. 2008; $1: 6$.

[15] PS Banerjee. Various Biological Activities of Pyridazinone Ring Derivatives, Asian J Chem. 2011; 23(5): 6. 